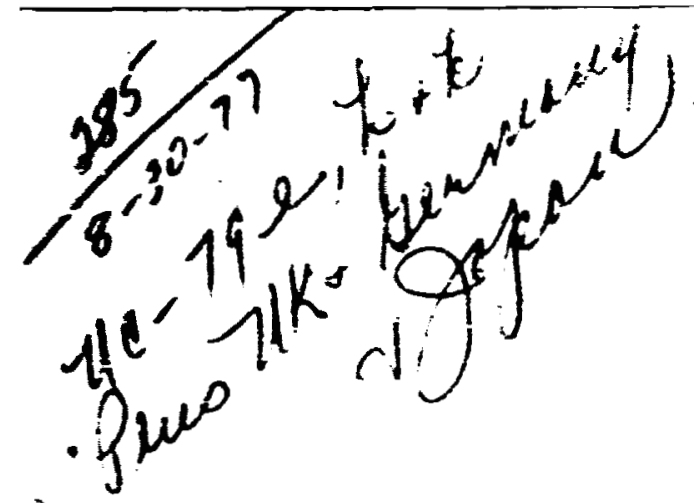

$$
\text { Ar \#i3o? }
$$

\title{
Treatment of Low Strains and Long Hold Times in High Temperature Metal Fatigue by Strainrange Partitioning*
}

ORWL/Sub-3988/i

S. S. Manson

Professor, Mechanical and Aerospace Engineering

Case iestern Reser:e University

Ronala Zab

Graduate Student

Case Eestern Reserve Univers:ty

\footnotetext{
- Firal report on research performed under Suiocontract No. 3988

as a part of the ORNI. High-Temperature Struztural Design Progran
}

Prepared jy

Mechanical and A.erospace Engineering

Cas - western Ruserve University

Prepared for

OAK RIDGE RATIONAL LABORATORY

Oak Ridge, Tennessee 37830

operated by

UN ION CARE IDE CORPORATION

for the

ENERGY RESEARCH AND DEVELODMENT ADMINISTRATION 
CiNL/Sub-3988/1

Dist. Category UC-79, $-79 \mathrm{e},-79 \mathrm{~h},-79 \mathrm{k}$

\title{
TREATMENT OF LOW STRAMS AND LONG HOLD TIMES IN HLH TEMPERATURE METAL FATIGUE BY STRAMRANGE PARTITIONING *
}

\author{
S. 5. Manson \\ Professor, Nechanical and rerospace Engineering \\ Case Western Reserve University \\ Ronald iab \\ Graduate Stivdent \\ Case hestern Reserve Liniversity

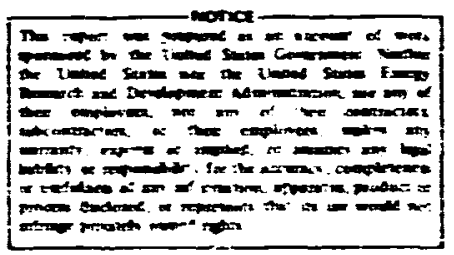 \\ * Final report on research performed unde: Subcontract No. 3988 \\ as a part of the ORNL high-Temperature Structural Design Progran
}

Date PuLlished: August 1977

\author{
Prepared by \\ Mechanicai and Aerospace Engineering \\ Case Western Reserve Iniversity \\ Prepared for \\ CAK RIDGE NAT IONAL LABURATORY \\ Oak Ridge, Tennessee $\mathbf{3 7 8 3 0}$ \\ operated by \\ UNION CARBIDE CORPORATION \\ for the \\ ENERGY RESEARCH AND DEVELOPMENT ADMINISTRATICN
}

Contract No $m-7405-$ eng-26

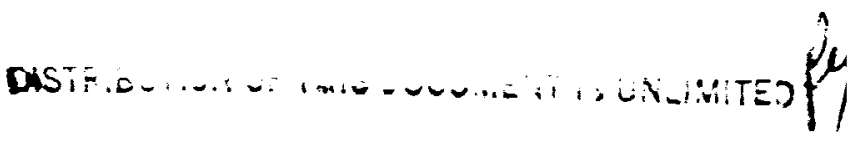


CONTENTS

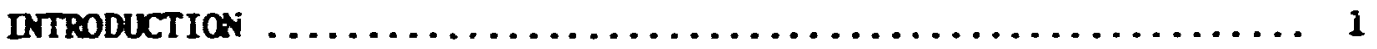

TREATMENT OF LOH STRAINS AND LONG HOLD THRES $\ldots \ldots \ldots \ldots \ldots \ldots, 3$

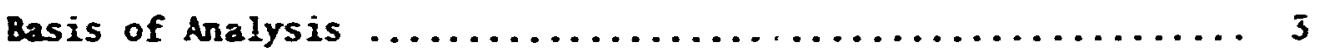

Extension to Treatment of Low Strains andior Long

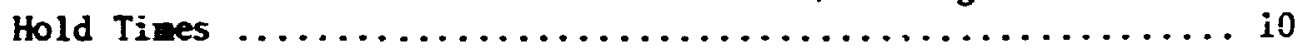

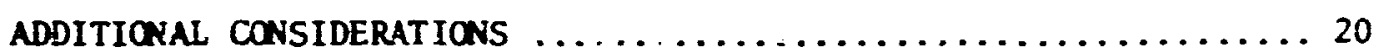

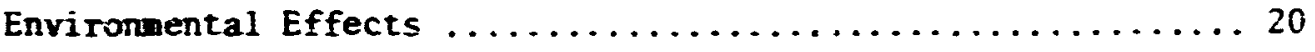

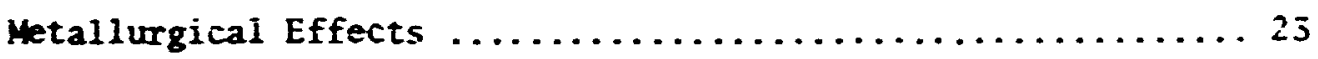

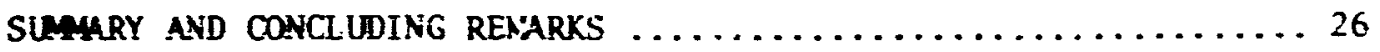

ACKNDMLEDGEMENT $\ldots \ldots \ldots \ldots \ldots \ldots \ldots \ldots \ldots \ldots \ldots \ldots \ldots \ldots \ldots$

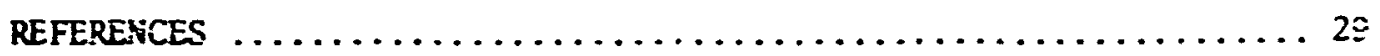

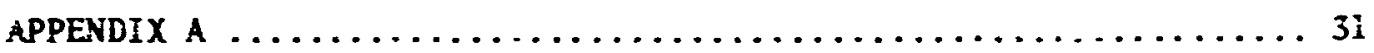


INTKGDUCTION

For the past $2 \frac{1}{2}$ years Case Western Reserve University has been engaged in a study on the possible applications of Strainrange Partitioning (SRP) to the treatment of high temperature creep-fatique probiems. One part of this program has been supported by the Oak Ridge National Laboratory, and is directed at special applications invoived in advanced nuclear reactors such as the liquid metal fast breeder reactor. The first phase was the preparation of an Interpretive Report describing various aiternatives for treating creep-fatigue problems, emphasizing Strainrange Partitioning as $\bar{c}$ method which has merit for this application. Wile many features of tive method were described in this report, and in fact much new progress was made during its preparation, a number of developments were left for future rtudy. As a rezint of the report a limited follow-on contract was initiated on May 1, 1976 and expired on September 30, 1976. it is the purpose of this report to describe in brief the progress made during the contract period.

The focus of study during this deriod was the treatment of low strains and long hold periods, since these were major areas requiring further investigation, as identified in the Interpretive Report. We shall, therefore, concentrate here on the progress that has teen made on this subject. However, brief discussions will also be presented on other subjects which have only been cursority studied. These are environmental effects, metailurgical effects, and grain size considerations.

One of the major conclusions reached in the Interpret:ve Repcrt is that there is an urgent need for developing techniques for trating low strains, particilarly when long hold-times are involved. wone of the candidate merhods for handling creep-fatigue proslems can readily address this subject without additional prongess beycid that available at the time of the Interpretive Report preparation. Strainrange Partitiraing. *Chapter 4, Ref. 1. 
in particuiar, concentrating as it does on the inelastic strains developed during the service cycle, must therefore be extended before it can be confidently applied to LAFBR components inrolving low strains. This is especially true when long hold-times are involved because of the transfer of one type of strain to another during tine ivici puer ivus. Since environment can affect both the rheological behavior, as well as the fatigue and fracture behavior, it is clear that the extension of Strainrange Partitionizg into the 10w strain (and) long cycle time regime wiil involve either:

a) the establishmerit of accurate constitutive equations in the strain/time/environment regime of interest so that the cyclic strain can be appropriately partitioned into the components characteristically used in the Strainrange Partitioning life relations, or

b) the semi-experimental approach wherein the hysteresis loop for the actual cycie of interest is experimertally determined. While precluding the need for accurate constitutive equations which determine the stresses and total strains involved in the cycle, there still remains the need for practical procedures for partitioning the measured total strains into strainrange components characteristicaily used in the SRP iffe relations, or

c) the engineering estimation of some of tre required stress or strain quantities, and the computation of the remainder of the quantities using simplified constitutive equations, thereby determining an internally consistent set of stresses - d strain components characteristically required in the SRP life relations.

Whichever of the above methods is ased, some account must be provided for the environmental effect. This subject can be given only cursory treatment here, but is obviously o: greac importance in components expected to operate in oxidizing environments at high temperatures for periods up to 30 years or more.

Hethod (a) atove will become viable when the extensive program on development of constitutive equations is completed. If, through these equations, each increment of plasticity, transient creep and steady state creep is determined at each increment of load or time, it then becomes a 
simple matter to formulate the $P F, c p, P C$, and $c i$ strain components that develop for the cycle. Hence there is no protlem in applying the SRF life relations, even when the inelastic components are small. Under these conditions the whole problem degenerates to a simple aporoach directly analogous to the treatmerit of large strains already developed. For this reason, this approach will not be further discussed here, except to express the hope that the final development will soon te realized so that it can be of direct use in SRP application.

The other two approaches have therefore oeen followed in this limited program. Examples of results to date will be described in the remainder of this report.

TREATMENT OF IOH STRAINS AND LONG HOLD TIMES

\section{Basis of Analysis}

The development $c$ f the procedure will be $j^{\prime}$ lustrated here by first treating iarge strain problems for which experimentai data are available to check resuits. We shall illustrate both the semi-experimental procedure, and the approach invilving an engineering estimation of live esseritiai fauturcs of the hysteresis loop required in the analysis. Then we shall extend the concepts to the treatment of low strains by the same principles. The procedures will be applied to problems involving hoid times in tension or in compression, combined tension and compression holf, and continuous cycling at various frequencies. In the initial anaiysis we shall neglect possible changes in ductility due to exposure. Later in tne report such ductility effects will be briefiy considered.

Basic Jata Required In order to treat creep-fatigue problems by Strainrange Partitioning it is desirable to know a number of properties associated with the material and some informantion associated with the particular problem being treated. Usually the information will be readily available through basic material characterization, but even if not known accurately it may be possible to estimate the required quantitites with reasonable accuracy. In the discussion to follow we shall assume that the required information is available for large as well as small strains; if sma! i strain information is difficult to obtain directly, it will be assumed that the determination 
is made by simple linear extrapolation from high strain data. He shall illustrate the proceciure in connection with problems of moderately high strainrange because these ar? the only ones for which good experimental data are available whereby the adequacy of the generai procedure may be checked, but there is no problem in extending the procedure for protlems of small strain. Thus, we shali show results of calculations invoiving small strains although there are, of course, no extensive data available to check the validity of these calculations.

Figure I shows the ideal type of data base desired for life analys is by this method. In Figure $l(a)$ are show the basic life relations for $\Delta \varepsilon_{p p}, \Delta \varepsilon_{c c}, \Delta \varepsilon_{c p}$, and $\Delta \varepsilon_{p c}$ types of strainranges. They are shown as sildly-temperature dependent functions, aithough for at least two materiais (316 SS and $2 \frac{3}{4} \mathrm{Cr}$ - I Mo steeis) studied (Ref. 2) they were found to be essentially independent of temperature. Also included in this figure is a fanily of elastic (el) lines, obtained from rapid cycling in association with $\Delta \varepsilon_{p p}$ tests. These lines are temperature-dependent, reflecting the flow strength dependency of the material with temperature.

Figure $l(b)$ shows the $c ; c l i c$ stress-strain curve, $O A$, for rapid cycling of the material. There is, of course, an interdependence between $O A$ and the pP and ei life lines of Fig. l(a). For any selected life value, the el line can be used to determine the stress range, and the $e l$ and $p p$ lines together can be used to determine the total strain range. Thus the curve OA can be constructed from a knowledge of the life relations. In this approach the implication is that plastic strain is always present, even at very low stresses which appear to lie on the linear (elastic) portion of the curve: but the deviation from linearity is very small. It is advantageous to regard a pp strain to be present at all stress rangez because it enables the deterninations of plasticity strains, even though they are small, when treating low total strains. Also shown in Fig. $1(b)$ is the rapid-cycling hysteresis loop ABCDA for one strain range. This loop can be constructed from the shape of the cyclic stress-strain curve through application of the well known double-amplitude construction principle. That is, CDA can be constructed 
from a knowledge of $O A$ by choosing $C$ as the origin and doubling al? stress and strain values aleng $O A$. Similarly, $A B C$ is sjmmetrical to CDA. Althougn only ore cyciic stress-strain curve and nysteresis loop is shewn in Fig. $1(b)$, numerous curves could be drawn, one at each strain range. These curves are all quite sensitive to imperature, being a reflection of the rheologica! dependence on temperature, but once the pp and el lines in Fig. $I(a)$ are known for a selected temperature any required hysterfsis loop in Fig. I(b) can be constructed.

The third desirable ingredient is shown in Fig. 1(c). It is the relation between stress ar.d secondary (steady state) creep rate in a cyclic creep test for in any cyclic test inveiving stopping at specific stress levels and observirn the creep, ate once it has stabilized). in Ref. 3 it was shown that the relationship between seccndary creep rate and stress can be represented by a power law. Thus Fig. I(c) shows linear olots of creep rates and stress on log-log coordinates. These curves can be expected to be strongly dependent on tomperature. For illustrative purposes the lines for different temperatures are shuwn paraliel, but other geom tric relations are possible.

The final ingredient of the life aralysis is shown in Fig. Tid). It is a stabilized hysteresis loop for the duty cycio under analysis. The tick marks represent the time sequence at which various points are encountered during the cycle. Although an experimentally determiried hysteresis loop is highly desirable, it is not absolutely necesiary. In its absence it can be approximated from other specified variables (for example, linear stress ramping as later discussed or other pattern of stress or strain variation). However, it should be emphasizsd that hysteresis loops stabilize rapidly, and it is necessary to traverse only a small fraction of life expectancy in order to obtain this valuable adjunct to the analysis, or to provide valuable information usefu? in crosschecking some facets of the analysis. 
Outline of Procedure To illustrate the procedure we shall analyze a test reported by Comway et al (Ref. 4) involving strain-hold to longtimes $(1.0 \mathrm{hrs}$ per cycle). The strainrange for these tests was high (2\%), but it will be seen that exactl: the same pro.edure as discussed for this high itrain probiem can be used to analize low strain problemis. In fact, we shall show results for such calculations after we have described the method.

The ingredients analogous to Fig. 1 appiicable to this problem are sinom in Fig. 2. Since the test was conducted at a constant temperature of $1200 \mathrm{~F}$, only this temperatiare is refiected in Figs. $2(0, \dot{C}$, and $\mathrm{d})$. Fig. $2(\mathrm{a})$ shows the strain pattern imposed as the test corfition, and fig. $2(e)$ is the stress-strain response, showing the riaxation that was measured during the strain-hold period. The time markings on Fig. 2(e) correspond to points selected in Fig $2(f)$.

The analysis is shown in fig. 3. First the sec!indary creep is calculated in each half of the cycle. Since the conpressive half of the cycle involyes only rapid loading the creep is iegligible; only the tensile half involves creep. Fig. $3(a)$ shows the cres rates and the integrated area (representing the totai creep strain) as .000975 . In Fig. 3 , item (b), it is also shown that the plastic strainrarige is .0160 as deduced from the stress range (elastic stranrange) and the life relationships of Fig. 2(a). The total inelastic soritange is .0167, as deduced from the width of the hysteresis loop, fr.m which the transient creep strainrange is determined by substracting the plastic strainrange.

It ther: becomes possible to calculate the strainrange components. As ciscussed in Ref. 5 the "creep" in each half sycle consists of the secondary creep p? us 10\% of the transient creep, if identified. Since in tnis case the transient creep is known, the total tensile creep, item (e), is .001045. Now, since the "creep" in the compressive half of the cycle is zero, there can be no reversed creep; tinus ${ }^{n} \varepsilon_{c c}=0$. Ail the tensile "creep" is reversed by plasticity; thus $\Delta \varepsilon_{c p}=.001045$. The remoinder of the ine?astic 
strainrange is converted to reversed plasticity $\Delta \varepsilon_{p p}$, and is .015655 , according to item ( $c$; of Fig. 3. Thus, this problem involves $\Delta \varepsilon_{c p}$ and $\Delta \varepsilon_{p p}$, and as shown in item $(j)$ and $(k)$ results in a computed 1 ife of 155 cycles. This compares to a measured life of 103 cycles, wrich is a reasonably close correlation. Similar calculations were iads for the other two $2 \%$ strainrange hold-time tests reported by Coriway in Ref. 4 In one the hold-time was $60 \mathrm{~min}$. and the other $30 \mathrm{~min}$. Life predictions were successively 156 and 149 cycles, compared to the experimental values of 117 and 76 respectively.

Alternate Procedure Before presenting the calculations for small strains it is appropriate to describe an alternate procedure for hardling the stress relaxation problem just discissed. In the previous discussion it was assuried that the stress pattern during the relaxation is known from experimentai observation. Suppose, however, experimental determination is inconvenient, can we stili handle the problem? Initially, let us assume that the maximum stress is kno:yn from the strainrange and cyolic etress-strain curve. "nat is, in Fig. 4 we assume that RP follows the cyclic stress-strain curve (by the double-amplitude rule of stress and strain, fig. (b).) Recognizing the iarge strain zmplitude of $2 \%$ ilivoived in this probiem, we reasonaily assume tha: the siresses at $R$ and $P$ will be approximately equal in magnitude; thus there is no ambiguity as to the coordinates of point $k$ in the initial construction of the hysteresis icop. The stress $\sigma_{p}$ at point $P$ wili be known in magnitude. The strass pattern $P Q ' Q$ car then be deteriiined from a single creep relaxation a alysis as follows:

Letting $\varepsilon_{c}$ be the creep strain at any time $t$ after the initiation of hold, and also lett: $: g$ :

$\varepsilon_{e}$ be the relaxes elastic strain at this time and $\sigma$ be the relaxed yalue of stress at this time, then, neglecting primary

(transient) crtep, and considering only the secondary creep rate

$$
\dot{\varepsilon}_{c}=A_{\sigma}{ }^{n} \text { or } \frac{d \varepsilon}{d t}=A_{\sigma}^{n}
$$


from the power-law relation shown in Ref. 3 wherc $A$ and $n$ are material constants dependent on the temperature.

By Hooke's Law $d \varepsilon_{e}=\frac{d \sigma}{E}$ or $\frac{d \varepsilon}{d t}=\frac{1}{E} \frac{d \sigma}{d t}$

But since strain is held constant $\frac{d \varepsilon_{t}}{d t}=\frac{d \varepsilon}{d t}+\frac{d \varepsilon}{d t}=0$

Combining (1), (2) and (3) results in $\frac{d \sigma}{\sigma^{n}}=-A E d t$ Integrating ey (4),

$$
\frac{\sigma_{Q^{1}}{ }^{-n+i}}{-n+1}-\frac{\sigma_{p}^{-n+1}}{-n+1}=-A E[t-C]=-A E t,
$$

or,

$\sigma_{Q^{\prime}}=\left[F^{-n+1}+\left(r_{-1}\right) \text { AEt }\right]^{\frac{1}{-11+1}}$

After the entire ho?d-period $t_{H}$, the relaxed stress becomes

$\sigma_{Q}=\overbrace{p}^{\sigma_{p}^{-n+1}+(n-1) A E t_{H}} ?^{\frac{1}{-n+1}}$

For the problem illustrated in Fig. 2, the application of the doubiear:plitude cyclic stress-strain relation resuits in a stress $\sigma_{p}$ of 41.87 $k s i$, and since the constants in the creep equation (i) are known from NASA data (Ref. 5) or unpublished data obtained during preparation of Ref. 5

$$
\begin{aligned}
n & =7.14 \quad A=2.55 \times 10^{-17} \text { ( } \sigma \text { in } \mathrm{ksi}, t \text { in seconds) } \\
E & =22 \times 10^{3} \mathrm{ksi} \\
\text { Thus } \sigma_{Q} & =[\mathrm{p}-6.14
\end{aligned}
$$

4 plot of stress relaxation according to Eq. (8; is shown in Fig. 5 (a); the agreement is remarkably good considering the basic approximations invis?yed and the fact that the creep rate determinations were made by dif. ferent investigators and on different lots of material from those involved in the relaxation tests, and that transient creep was omitted. To check the validity of this approarh to other tests, additional calculations were made for the two other relaxation tests reported in Ref. 4 . The temperature 
and strainrange were the same as above, but in one case the hold time was $30 \mathrm{~min}$; in the other $1 \mathrm{~min}$. The results are shown in Fig. 5(b) and (c). For the $30 \mathrm{mir}$. hold test, the agreement is still very good; for the $1 \mathrm{~min}$. hold the effect of the transient creep is apparent in the early seccids, but after about $30 \mathrm{sec}$ the apreement again becomes excelient.

The next step is to determina how much of each strainrange component type develcps during the cycle:

a) The total amount of plastic flow during the tensije haif is known from the cyclic stress-strain curve, or as expressed by the linear life relations, shown in Fig. $4(c)$. Knowing the stress range $R P$, tre elastic strainrange establishes the point $M$ on the elastic 1 ife lire, from which the point $N$ or the piastic life line vertically above $M$ establishes a plastic strainrange of .0160.

b) The tensile rereep is equal to the elastic strain from $P$ to $Q$ (or alternatively, the integrated creep during Pú according to Eq (1) above, which yields exactly the same result.) Thus, in this case the tensile creep strain is .000975.

c) A small amount of ambiguity develops in the determination of the compressive plasticity if determined from consideration of the shape of the curve $2 R$. We cannot construct this reverse piece of the hys ieresis loop from the double-amplitude cyclic stress-strain curve alone, starting with $Q$ as an origin. The $p_{i d s}$ tic flow frum $Q$ to $R$ based only on the stress range involved would be expectad to be toc low to balance both the tensile plastic and creep flow. Actually, a more approp;iate way to construct the compressive half of the loop is to add the imaginary segment PTQ in Fig. 4!a! so that TQR, in conjunction with the cyclic stress-strain curve yields a compressive plastic flow which is equal to the tensile plastic flow plus the relaxation creep flow. This adds the complication trat if $o_{T}=G_{R}$ then $\sigma_{p}$ is no longer equal to $\sigma_{R}$, which was our original premise. Therefore the problem becomes one of trial and error to determine the appropriate location of the hysteresis loop to estal lish consistency with the rheological behavior. In general, the rneological tehavior, as affected by the cycle itself, influences the individual creep and elasticity components This is evident in Fig. 5 wherein it is noted that the maximun tensile stress reached depends on the hold-time. The longer the hold time, the lower 
the stress. To get exact behavior, the constitutive equitions ast be better escabiished than they are now. But the approxinate ariswer can readily be deternined in tiis case by stating that the behavior of $Q R$ in the vicinity of $R$ is such that the plastic flow developed on comprission is equa? to the tensile plastic fiow plus ta.- tensile creep flow during $P Q$.

d) Thus, from the above considerations, the $\Delta \varepsilon_{c p}$ deformation is equal to the tensile creep deformation .000975 , and the remainder of the inelastic strain in $\Delta \varepsilon_{p p}$, so that $\Delta \varepsilon_{p p}=.0160$.

e) The life is then caiculated by the Interaction Darage Rule as

$$
\begin{array}{rlrl}
f_{p p} & =\frac{.01573}{.01670}=.9419 & \hat{f}_{C p}=\frac{.000975}{.01670}=.0581 \\
N_{p p} & =233 & N_{C p}=25 \quad \text { from fig. } 1(\mathrm{a}) \\
\text { and } \frac{.9419}{233}+\frac{.0581}{26} & =\frac{i}{N_{f}} \quad N_{f}=159
\end{array}
$$

This iife compares with the measured value of 103 cycles, which is well within the commonly acceptas?e factor of 2 . Hote that this caicuation made no use of experimentaliy determined hysteresis joops or stress relaxation patterns. The calcuiations are still quite satisfactory, despite the neglect of transient creep, although the inclusion of transient creep did improve the predictions somewhat.

Fig. ( shows a sumary of calculation: made by the above procedure for additional hold tire tests $l i k \in n$ from kef. 4 . The predictions agree well with the experiments. We alsc note that the degree of ayreenent be ween prediction and experiment does nut cecrease as the total ost time increases.

Extension to Treatment of Low Strains and/or Long Hold Times We shall now extend the capse cuncepts already described in connection with the treatment of large strains to the study of low strains ard long hold times. The elements of the procedure are:

a) The detemination of the plastic strainrange from knowledge of the stress range and the log-linear iife relations of elastic and piastic strainranges.

b) The determinaticn of secondary creep strains by integrating the equations reiz:ing creep rate to a sower-las of stress. 
c) Determining transient (or primary) ireep strains from actual observations of tota! creep aurirg any interval and substraciing the secondary creep strains. This step is optional, and is onitted if experimental facilties are unavailablis or if a somi-experimental phase is inconvenient.

d) Cor:structing tie strainrarige components $\Delta \varepsilon_{p p}, \Sigma \varepsilon_{p c}, \Delta \varepsilon_{c p}$ and $\Delta \varepsilon_{c c}$ from the determined creep and plasticity components in the tensile and compressive halves of the cycie.

e) Applying the Interaction Damage Rule to determine life.

Of sfecial importance is the Getemination of the stress values that ieveiop. To this extent the stresses wiil be known accurately either if directly measured by experimental observation of the hysteresis loos, or if accurate consitutive equations are avaijaile to track stress and strains during the cycle. However, in some cases neither approach will be practicai; then the calculations will involve engineering approximetions. We shail illustraie a case in which such ajproximaticas are required, their choice being mate to incroduce some conservatism in the resulting life estimates.

Combined iersile are Compressive hiold Periods we firs: treat the case in which both tensirn and compression huid periods arz intrcduced in probiers invoiving ior strainiange. It will be seer that this case lends itseif more readily to the Estimation of the hysteresis loci jeveloped because of the symetry of the ore?e. Fis. 7 illustrates che pocedure. we star: with the recognition that because of tia symetry of the ioacing cycle, the hysteresis ioop will be symetrica: in the tersile and comoressive haives. Then the iysteres is $\mho_{p}$ wiil be $A B C D$ for the strainrange $\therefore E$. There, is, thus, onij one unkrowrigiantity in this analys is, for examole : $B$. Ince we krow $\delta_{\mathrm{E}}$ and the hold time, we can determirs - from tie rlaxation. equation ( 7 ), anc oi course $\sigma_{D}=n{ }^{\circ}{ }_{A}$ follox froui considerations of symetry. Because of the non-? inearity of the probie: however, it is converient to start $y^{\text {th }}$ the assumption of known strecses and to determine the combinations 
of strainranges and hold times that will gonerate these stresses. For exaple, in Fig. 7 , suspose were concerned with the solution for a strainrange $\dot{\Delta \varepsilon}=0.5 \%$ and various hold times. $\dot{A}$ convenient approach is first tc construct a complete hysteresis loop MABNCDM for an arbitrariiy selected strainrange, say under rapid cycing. This can readily be done from the cyciic stress-strain curve, ior the iinear life relations for elastic and plastic strairrange under rapif cycling at the temperature of interest,e.g. the pp and el lines in Fis. lifa).

Vertical lines $A D$ and $B C$ can then be construrted at equal distances from the vertical axis and at a strainiange of $0.5^{\circ}$, to determine $t$ : o sjecific stress values $\sigma_{A}, \sigma_{B}, \sigma_{C}$, and $\sigma_{D}$. It can then be immediately determined wat hold time $t_{H}$ is required to re! $a x \sigma_{B}$ to $\sigma_{C}$ (or $\sigma_{D}$ to $s_{A}$ ). Since the partitioning of the hysteresis ioop ABCD into creep and plasticity romponents can readily be accomplished ieven when curvature is present along $A B$ ariu $C D)$, the strainrange cumponents are easily establisted. Of course, becalse of symetry, oniy $\Delta s_{p p}$ and $\Delta \varepsilon_{c c}$ develop, and in fact for sma?l Le the ineiastic strainrange developed is almst entirely $\therefore=\mathrm{cc}^{\circ}$. In either case the iffe can readily be calcuiated from the Interaction camage Rule. Thus the calculdtion providss one point relating the life to $A E$ and $t_{H}$. Aoditional foints can se obtained from the same loop w by selecting a new value of $\Delta E$ and repeating the f.ciegure to cietermine a new rold time and life. in a siailar manner, by chiosing a new value of 's, (say $s^{\prime} \alpha^{\circ}$ ), and pruceeding with a spectrum of choices of $\Delta \varepsilon$, a nriv series of corresponding values of hold-iine and life values can be computed.

The calculations can then be depicted in their entirety as snown in Figs. 8 and 9 . Whall discuss these figures later, after presenting resuits for calculations involving hold :imes only in tension or on? $y^{\prime}$ in compresioion.

Tensile hold Periods Treatment oi only tensile hold probiems is not as straightforward as symetrica? tensile and compressive holds because of ambiguities that develop in the rheological behavior at low stress ranges. ionsider, for example, the two extrexes of behavior possible when a specimen is cycled at low strainrange and tensile hold periods are introdiced. In fig. 10(a) the behavior is depicted as involving little or no 
plasticity during the reversal because of the small striirirange invclved. 1i. :he first loading the stress-strain path is zlong OA. Although, accordirig to the procedur: adopted herein, ail stress applicatioris imply plastic strain (e.g. see Fig. 4(c)), the actual amount of flasticity is negligibly small if the tota? strainrange is all erouyh; tnerefore we show line of as a straight line. A hold period at the maximum strain can, however, result in stress relaxation to point $B$, if the hold period is long enough. Thus, upon reverse loading the path is $B C$, which we again assure to be at strainrange low enough to preclude signilicant piastic deformation, causing $B C$ to be a straight line. Since there is no hold period at $C$, and reloading is assumed to occur as rapid as possible, the subsequent inading is along the identica? lire $C B$. During the hold period relaxation again eccurs along $B D$, an amount smaller than $A B$ because the stresses involved are lower and times are assumed to be the same. The proces: is tion repeated in subseguent cycles, each time the maximum tensile stress becuming lower and the maximum compressive stress becoming higher. Eventually a quasi-stabilized condition may be achieved aiong FG, wherein the stress at $F$ is low enough to preclude appreciable further stress relaxation. But in principle, at least, the maximum stress can ccntinue to relax during the hold pericd, eventually approaching zero. This the final stabiiized condicion invoives no cyclic inelasticity involving creep, and extremely small plasticity dependent only upon the strainrange. With the small plasicity jeveloped, and tne negative mean stress along $F^{\prime} G^{\prime}$ the fatique life can become very ing. In fact, the longer the hold time the lower will be the rumber of cyrles required to stabilize to the low peak tensile stress, assuming this type of rheological behavior. Thus, assuming this type of behavior, the longer the hold time the sigher the possible cyclic life.

The other extrene of tehavior is shown in Fig. 10(b). Here it is assumed that the scabilized loop becomes $P Q n$ and that irie creep relaxation duri.ig $P Q$ somenow, either because of the deformation or the high temperature exposure, softens the material in reversed loading, so that $Q R$ develops the plasticity required to balance the creep occurrins during PQ. Tree specimen this develops a $\Delta E_{C D}$ strainrange. Obviously the higher the stress at $P$, the higher will be the $\Delta \varepsilon_{c p}$ strainrange, and the lower the cyslic life, for a 
given hold time. In general, it can be expected that the peak coxpressive stress at $R$ will be higher in agnitude than the peak tensile stress at $P$. Thus the lanest cyclic life will result when $o_{p}$ is as close as possible to $\sigma_{R}$, say equal. The life in this case can beccme substantially lower than that for the cycling of Fig. $10(a)$ and aiong $F^{\prime} G^{\prime}$.

Frac the aboye discussion it is apperent that the factor that most sigaificantly governs fatigue life is the rheological response of the material to the imposed loading, not so such the method of calculating the iife once tre rheological response is known. This area of establishing accurate constitutive response to know imposed loacing is a very inportant subject, and requires mich further study. However, in order to trea $i$ ine jrotulam in a conservative manner it will be assumed that case 10,b) actually develops, and that $\sigma_{p}$ is haif the stress range that is calculated for the strainrange $\Delta \varepsilon$, as deteimined from the double-amplitude concept of constructing hysteresis locps from the basic life relaticr lines. For smail strainranges the maxime siress will be approxinately the product of elastic modulus and half of the strainrange; but the ap?roacis using the double-aplitude concept will be vaijid even for iarger strainranges wherein curvature develops aiong the loading path.

Figures 11 and 12 show the results of conservative life calculations made for a spertrum of strainranges and hold times assuming the rheological behavior to be that of Fig. 10(b). For each st? acted strainrange the line ap was firsi constructed according to the double-amplitude loading path concept, int the stress range determined. The stress at $P$ was assumed to be half the sirsss range involved, and starting with this time the relaxation $P Q$ was determined using Eq. (6) for the krown hold time. The exact shape unloading path $Q R$ did not enter into the calculations except that the initial portion of the unloading $Q S$ is parailel to an elastic 1 ine. T.us the strain developed is a $\Delta \varepsilon_{c p}$ equal to the relaxed strain duriag the $\mathrm{PQ}$, and a $\Delta \varepsilon_{\mathrm{PP}}$ strain associated with any curvature developed along pe (negligible for low strains, but included in th a calculations shown for the large strainranges). 
Compressive Hold Periods Treatment of hold periods inposed enly during the compressive peak strain is identical to that for tensile hold periods. The rheological calculations are the same, and the dilema regarding actual response to imposed loading is 17 so the same; the only difference is that $\Delta \varepsilon_{p r}$ develops for compressive hold, whereas $i \varepsilon_{c p}$ develops for tensile hold. ihe life relationships are, therefore, different. Resuits of the calculations are shown ir: Figs. 13 and 14.

Continuous Cycling As a fina? example of extension of SRP anaiysis to low strainranges we consid:r zon:inuous cycling crer a range if frequencies. If the cyciing is carried out ry controlling the strain rate, for exampie, at a uniform rate of either tatal strain or inelastic strain, as has been common in many recent experimental programs, a means is required to establish the stresses that develop. Either accurate constititive equations or the quasi-experimental approach of determining the stabilized hysteresis loop provides the necessary stress information to proceed by the principies already described. If the probiem is one in which the stress pittern is specified, then no further rheological information is needed to perform the analysis. In the following illustration we shall assume the stress is symetric3lly ramped iiriearly to selected tension and compressive peak vaiues. Tia strain levels are not specified; rather they are derived from the stresses and ramping rates as the consequential combined creep and plasticity values. To analyze the data, and to cast them in a form commonly used in creep-fatiyue analysis, hewever, they are cross-plotted to obtain life along lines of constant sirainrange.

A sample computation is datailed in Fig. 15. The frequency is $10^{-5} \mathrm{~Hz}$, arid a st-ess amplitude of $i / k s i$ at a temperature of $i 360 F$ is issumed. Since the stress is ramped linearly its value is known at each irstant, and the creep is calculated in step 1 from the known creep rate relation in terms of the power-law of stress. Steps 2 anci 3 utilizo the known stress range to determine plastic strain range, using the life relations. From symmetry $\Delta \varepsilon_{p p}$ and $\Delta \varepsilon_{c c}$ are determined in Step 4 , and $f_{p p}$ and $f_{c c}$ in steps 5 and 6 . The Interaction Lamage Rule is then applied in step 7 to obtain iife. Thus, 
as show in Fig. 15(b) the point $P$ or the line of $10^{-5} \mathrm{~Hz}$ can be plotted with $\Delta \varepsilon_{t}=.05398$ and a cyclic life of 4,398 cycles. Other points along the $10^{-5} \mathrm{~Hz}$ curve can be obtained by se'ecring arjitional values of peak stress and repeating the calculations. - inis manner the conplete curve for $10^{-5} \mathrm{~Hz}$ as wali as otrer frequencies were established. The results are show in rig. 16. Cross-plots of the infurmacion in Fig. 16 are shown in Fig. 17 with strainrange as a jarameter are shown in Fig. 17. In Figure 17 the numbers next to the tick marks reprasent the selected stress ampl !tude that generated that point.

Results of calcuiations for 1200F are shown in Figs. $: 8$ and 19, which are araiogous to Figs. 16 and 17 . These calculations provided a means to make a compariscn between calculations made in this manner with experiments available from the literature. Although the literature results (Ref. 4, p 38) were obtained by ramping titai strain at a constant rate, while the calculations were made for constant stres; rate ramping, the agreement is very good when the comparison is shown in Fig. 20 . It is seen what the degree of agreement is about as yourd at the low valuec of strainrange as a the high vaiues, and at the hich vaiues of tcial test irie as at he low vialues.

Discussion The foregoing calculations show that strainrange Partitioning readily lends itself to the treatment of low strainranges and long hold times. The principles involyed in such calculations are similar to those used in the treatment of large strairs. hivere direct comparison between calculations and experiment has teen possible, the zzreement has been very good. An important point in this connection is that the data entering into the: calculations are totaily independent of the experiments predicted. Thus, fo: examp?e, the tests conducted to determine creep strain rate as a function of stress, and the generic SRP life relaticns, are totally independent of the haid time and continuous cyclirg tests predicted. In fact the tests were conducted by different investigators in different laboratories on separate lots of material. The fact that agreement is obtained at the strainranges where data are available, despite the diversity: of testing conditions involved in basic data generation and experinents 
conducted in comparison to predictions lends some credence to the concepts of Strainrange Partitioring. However there has teen no opportunity to check predictions against test zesults involving very low strainranges or very lorg hold times. Since these calculations invo!ve tre extrapolation of the SRP Iife relations to low strain values as well, it is ipparert that experimental verification is required for the approach discussed. Not only the basic iffe relations and the procedure, but the rheological tehavior so important in governing the parameters that enter into the calculations, require future study.

Some interesting results and proolems raised by the calculations wil: now be discussed. Figures $8,11,13,17$ and 19 show the effects on cyclic life of varying hold times for selected values of total strainrange. For the figh strainranges the eifect of long hold is relatively small because longer hold only causes conversion of a small percertage of the total impcsed

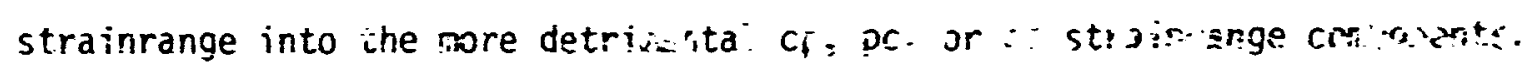

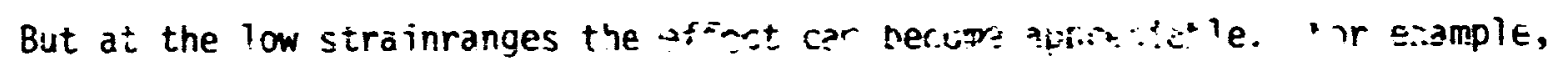

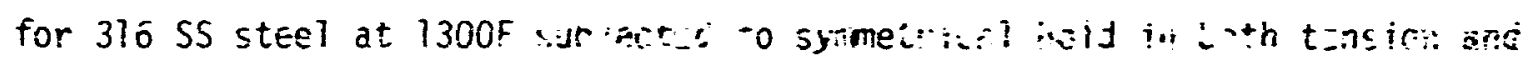

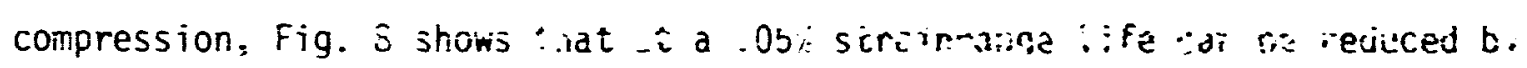
more than a hundred-fold far $>$ hundred-fi:d incre.

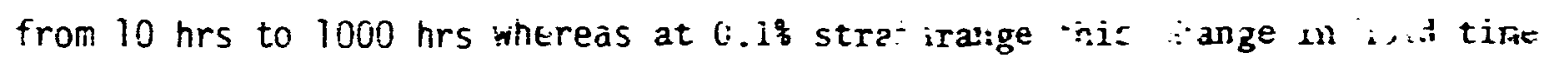
only reduces life by iess chan a factor of 10 . Bu, note, a-so, ini: : gh iife values involved. Even with hold 'ines :- ' $\mathrm{nn}$ hrs, 10.j00 cycles can be sustained at a strainrange of $0.1 \%$. The totis time is enomous. P?.-1ted in Figs. 8 to 19 is a dotted curve representim, 3r years of life. Note that the large effecis involved time ranges wherein the method cannot be exnected to be accurate tecause of the simplified assumptions involved and because of inevitable metallurgical changes.

In generai, ail life values tend to saturate at higher hold times as the total imposed strainrange tends to be converted to the most detrimental type involyed in the application (i.e. $C C$ in symetrical hold, 5 ig. 8; cp in tensile hold, Fig. 11; pc in compressive hoid, Fig. 17; and cc in stress ramping, Fig. 19). 
Cf special interest, tro, is the relative damage of the various types of hold period jatterns possible. Note, for Example, by comparing Figs. 11 and 13, that whlle tensile hold is more damaging than compression hold in the high strainranges, the compressive hold is wore damaging in the low strain-ranges. Tre reason for this iies in the slopes of the 1 ife ralationships for this aterial. Since the slope for the $p$ life is steeper than that for this cp life, extension to low strains causes the two tc intersect and to liverge in opposite directicns at low strains compared to the high strains. The transition occurs at a strain range of about .035:. This type of behavior has already been roted in the past for $2 \frac{1}{4} \mathrm{Cr}$ - I No steei for wich pc was noted to be danging to cp behavior at even hightr strain-ranges in the order of $1 \%$. However, the slopes of the two life relations were 21 so unequal, and at consicerably higher strainranges it appeared that $\mathrm{cp}$ dazage cocld also exceed the $\mathrm{pc}$ value. Thus it may well be that each material has its own cross-over value, and it is important to study in strains in order to obtain further insight. However, it shouid be noted that from a practical viewpoint tile crossover for 316 stainless steel occurs at times which are outside the usual range of practical interest. The eatter has only academic value.

A comparison of Figs. 8 and 11 is also interesting in this respect. At the high strain ranges of the order of and higher, the tensile hold appear: to be more damaging than the combined tensile ard compressive hold. At a strainrange of 0.1$\}$, tensile holds also seem more damaging than symimetrical holds at hold periods of $3 \mathrm{hrs}$ or less, tut less damaging for hold periods above $3 \mathrm{hrs}$. At a strain range of 0.05 symetrical hoids apfear to be more damaging than tensile holds over the entire range depicted. Again this is a reflection of the 1 near extrapolation of th. life relationships into the low strainranges, anc uires checking. In addition, it should be recalled that as discussec in connection with Fig. 10, tensile hold alone car result in favorable stress relaxation which reduces undesirable tensile stress. The calculations shown in $5 i g .11$ were made for the conservative assumption indicated in Fig. $10(\mathrm{~b})$ that the maximum tensile stress equals the compressive stress. Thus it can be seen that even with conservatisn the effect of tensile hold is not as detrimental at the low 
strains and long hold times relative tc symetrical holds in tension and compression as would be expected from test results at high strainranges. Sote also that as strair is cecreased lives increase substantially, but that most of the plot relates to times above the 30 year range of interest.

Figures $9,12,14,16$, and 18 show the same calcuiations with holdtime as the paraneter. These plots are analogous to conientional plots of total strainrange vs cyciic life which reflect two regions -- one in which the inelastic strainrange predominates, the other in which the elastic strainrange predominates. At the high strain ranges, where the inelastic strainrange predominates, ail the curves are steep, and relatively insensitive to hold time. Most of the strain is induced as the pp type, and hold time introduces only moderate anounts of $c p, p c$, or cc strain (depending on the type of hold pattern). Thus the life is little affected. The inelastic lines do increase some what in slope as nold time is increased in contrast, for example, to remaining parailel (as required by the Frequencylodified Life Equation). In the low strainrange level ie again see nearlinearity, but the lines fan out with considerable increase in slope as hold time is increased. Thus the "elastic-iine" analogue, by Strainrange Partitioning, is one of considerabie varying slope and deperds strongly on the nature of the hold period. But the very large differences in hold-time effect -cur at nominai times beyond 30 years.

Tie above behavior cannot, of course, presentiy be checked by experiment. However, we can compare the predictability in the ime and strainrarges that have been studied as an indication of what to expect as strainrange is decreased or totai test time increased. Some results are shown in Figs. 5, 6, and 20. Each figure shows that a reasonable agreement occurs between the predictions and experiments for the time ard ctrainranges tha: have been studied herein. If the ratio of experimental iffe to predicted life is flotted against either strainrange or hold time, these iimited data do not indicate any reduction in corservatism either as strainrange is ciecreased or totai test time increased. Further experistents to extend the ranges of strain and hold time are, of course, needed for conclusive resuits. Figures 11 to 19 should not be interpreted as final predictions by SRP, since there are many variables that have not yet been incorporated 
into the calcuiations, such as ductility variations iater to be discussed. The main point of the figures is to indicate that a simple procedure is available so calculate idealized lives according to the method, bit that further research is needed to incorporate additional realistic features.

\section{ADDITIONAL CONSIDERATIGNS}

The foregoing discussion was intended to indicate procedure for calculations, rather than to provide accurats final design iniomation. Figures 8, 9, and theil subsequent counterparts are, for example, very sensitive th extrapolation of life relations which are presentiy based on relatively little information in the hish strain and short life range. If similar figures were to be constructed for design use it would, of course, De necessary to extend the data base upon which the calculations are maje. He consider in the following brief discussiun several other factors in addition to the more accurats determination of the life relaticns and consticutive equations already emphasized.

\section{Environmental Effects}

Environnent is, of course, a major factor in governing fatigue iife, especiaily when dealing with long-time applications. It is weil knowr: that the presence of oxygen can substantially redice fatigue life, and that fatigue in vacuum or irert environment is usually considerably tətter than in air. In fact, it has been suggested by some investigators that high temucature fatigue digradation is entirely an oxidation affect. Tris proposal was based on the fiact that the high temperature fatigue properties of numerous materials in vacuum were about the same as their room tomperature fatigue properties in air, thereby pointing to oxidation as the degrading influence. However, all the fatigue tests on which this conclusion was based were of the continuous cycling type, inducing only pp and ce strains. One of the major contributions of Strainrange Partitioning was to point to the need for loading cycles producing $p c$ or $c p$ strains in order to bring out the fact that even in vacuum large degrading influences of the creep fatigue interaction could result. A number of alloys have been studied in high vacuum, among them the refractory ailoys $T-111$ and Astar $811 \mathrm{C}$ (Ref. E), Ač86 and 304 stainless steel (Ref. 7), and Rene' 80 
(Ref. 8). Ali have shown that a creep fatigue interactiois occurs even in vacuum. In general, an air environment reduces the fatigue froperties below the curresponding propertios in vacuum for the same type of :trainrange. The refactory alloys canot, of course, operate in air at high temperature because of their severe oxidizing tendencits; there is no point, thus, in comparing the fatigue froperties under the two environments. The iron base alloys A286 and 304 stainless steel improved in vacuum relative to air. The nickel base alloy Rene' 80 showed only minur degradation in air, however, becauce of its general oxidation resistance, large grain size, and low ductility in both environments. Gnly the pp life reiations fall appreciahiy in the air environment, and even a costing to protect from oxidation did not prevent this degradation. The results require further analysis before they can be completely explained. Fiom all the tests referred to abovo, the major conclusion emerged that while the properties are different in the air and vacuum environments, each material yielded to the cetermination of $p p, c p, p c$, and $c c$ life reiationships in exch environinent. Analysis using these life relations permitted th. a correlation of all the data obtained within that environment. Thus SRP was useful in analyzing data in a vaclium environment as weil as air.

Another point of significance in this respect was discussed in Chapter 4 of Reference 1. There it was pointed olit that such fatigue degradation as occurs from oxidation develops in relatively hort time and requires relatively little exygen. Corroboration was drawn from published research on a? uminum showing that a sharp discontinuity in the fatigue response occurred within a narrow range of pressure (about $10^{-2}$ to $10^{-3}$ Torr). Aoove this pressure the fatigue response was very little different from that in atmospheric air (760 Torr), and below' this pressure it was very little different from tinat in the bigh vacuum of $10^{-8}$ Torr. Thus it appec ned that if enough oxygen atoms were available to oxidize the freshly exposed surface caused by the plastic deformation leading to fatigue, increasing she amount oy a thousand-fold did not accelerate the process appre.iably. From this it minht be possible to deduce that extended periods in air do not riecessarily degrade fatigue much more than modes: exposures, as long as these exposures provide the 
critical amount of oxygen required for the basically rapid oxidation. If it is assumed that the normal determinztion in air of the basic SRP life relationships involves conditions adequate to provide the minimum oxygen requirements, then it can be concluded linat iittle correction will be required to apply these relationships in analysing long time tests.

Evidence that the above reasoning may be valid is shown in Fig. 21. These were data interpreted by ilalford (Ref. 9) in analyzing the Interspersion tests of Curran and Wundt (Ref. 10) sponsored by the Metals Properties Council. The tests were basicaliy of the cp rwoe of loading, and in analyzing the results tis.lford used the $c p$ and $\mathrm{pp}$ life lines for the $2 \frac{1}{4} \mathrm{Cr}-1$ Mo steel determined at NASA (Ref. 3) in tests lasting 160 hours or less. Yet the predictions of the APC data testing up to 5000 hours yieided approximately the same degree of correlation as the short tests. A small tendency for the experimental resuits to fall somewhat shorter of the predictions in the longer time range than in the short time range miy be discerned in Fig. 21 , iut this point needs further study. Note, however, that at an extrapolation in time by a factor of 30 , the agreement is stili very good.

It migh: be deduced from the abuve discussion that in conducting the test: to determire the life relations for use in the SRP analysis discussed in tine earlier se:tion of this report, the times involved should be of the order of $1 / 10$ to $1 / 50$ of the desired extrapolation times in order to insure reasonably vaiid extrapolations. This is ouite practical. If the tests take as much as one to tinree years, extensions to 30 years may be achievable. It thus appears reasonable to siggest that the basic SPF relations be generated from tests requiring approximately a 1-3 year duration. Loadholding tests to generate the $C D, p c$, ard $C c$ life relations can then use quite long hold-tizes in each cycle to consume the time requirec to cause the tests to be protracted to this duration. If the creep can be mezsured directly, then of course this should be done. If not, use of the power-? aw relation between stress and creep rate discussed earlier in this report can be applied by extrapolation to low stresses. 
Vacuum tests can al so serve a usəful pur \%se. First, by changing the pressure over a widc range, information call be obtained as to how much oxyger expcsure is required to produce varying degrees of oxygen degradation on catigue. Also such tests can help determine how much benefit might be achiered from the deveicpment of coatings or other surfice protection systems wnich excluie oxygen, aithough the question of surface coatings is complicated by metallurgical interaction between soating and substrate, and by the notching effect if the coating cracks.

\section{Petallurgicsil Effects}

Another factor that requires consideration is the metallurgical effect beyond the chemical interaction reprisented by surface exidation. Phase precipitation, for example, may have a nunber of effects. Ductility may change, tinus influencing fatigie. Or precipitates may change the creep resistance, thereby altering the creep rates in later cycles. In farticular, if the precipitates xccur in the grain boundaries, they can seriously alter the $c F, p c$, and $c c$ life relations. Thus care should be exercised to insure that any expected instabilities are accounted for in extending the life relationships to unexperienced time levels. Some reference to this subject has aiready been made in Chapter 4 of Reference 1 . Two important its were discussed. One of these is that temperatures which can ei: egrade or enhance ductility could seriously alter fatigue iff. In Fig. 4.43 of Ref. I i.t was ubserved, for exa.jle, that in the temperature range it 1190 to $3500 \mathrm{~F}$, IN-706 is associated with low ductility because of an oxidation-erhanced precipitate. The universalized SRP Iife relations, which use ductility as a normalizing parameter, suggest a quartitative reduction in fatigue in ait within this cemperature range. i:: vacuum, hciever, the oxygen-enhanced precipitate does not occur; the ductility is not reduced; and the fatigue pronerties co not suffer. Elevating the temperature above $1500 \mathrm{~F}$, however, avoids the precipitation chiancenert range, and the fatigue does not suffer at all. Thus the beneficial effect of vacuum is in suppressing the precipitation tendency, not protecting against surface oxilation. It is important to be alert to this factor in studying low strain and long time extrapolation because the effect may be both strain- and exposure time-dependient. 
The second point discussed in Wapter 4 of Ref. I is that it may be fossible to inprove the satifice sharacteristics involving the creep sode by causing a suitable pracipitate to develof in the grcin boundaries. It was poirt uu, fir exaple, that the $T-111$, wile sjailar in copositicn to the ASTAR $\triangle[1-C$, does not contain a precifitate in the grair boundary wereas the latter does. The fatigar properties in the wodes involvir: creep are wist tetter for the esterial contining the $q$-ipitaie which reta de grain boundary siliding. Thers we have a clue as to how to iepreve fatigur resistance timugh tie incorporation of a grain boundary precipitate.

Sizilar considerztion stouid te giver to grair size effects in tis cortext. The larger the grain size the less will te the tendency for grain soudazy sliding, and tite more a given iaposd strais will be absorbed in tia iess detricental pp deforwation. Thus it appears ihat sons castroi is avalatie to influence atigue properties $h$ heai rzeatment to de ilop roinal grain size. it would te desirable to study various processing variables such as working anc hest treatment, either individualiy or in conjuction with each cther, to deteraine optimu combirations for resisting high texperaiure creep fatigue interaction. Strainranga Partitioning offers some guidance as to the cesired effect by zegardirg the interacticn to a fizst approximation is one involving the intercraige between sip pisne sliding and grain bolubary sijing. It would then appear that larger grains to mininize grain bouidary areas, the deveiopment o: a precipitate to impede grin boundas: slijing, and thermonechanical processing to enhance creep and tensile ductility are desirable directions of approsth.

One of the sdiariages of Strai. rarge Fartitioning as a means of tieating the creep-fatigue interaction is that it provides 3 iramewcrk for including the possible effects of ductility variations during the serice life of the component being anziyzed. Since the universiized life relations are noraalized with respec: to duitility, changing ductility can be included by considerrig small time increments furing wich ductiiity car. be regarded constant. The approach was first usej in Ref. Il te $t_{i}:=$ fr quency effects in A-286 which was known to have 3 time-iependent c: ef tu:tility. The rssults are sumarized in Fig. 22 (taken from Ref. 11). Note 
that the $x=0$ life erve inanges with frequency bocause the life depends on frequency, whisi in turn governs crep dictiisty. The effect inds to procuce a 'oxer cyclic life at the lox frequencies than wous i have heen predicted if creep ductility did not change with life, becalise the lower the irequency the longer is the chronological life (i.e., hours, i.ot cycles;, and this reduces the eftective creep ductiinty.

The method was also useci in Chapter 4 of pef. I to pruvide a guideline as to the possible generai effects of ductility raductions during the lifetine of a component. In this cast the calculations were based on linear reductions in ductility with time. The resilts are sumarized in fig. 23, takeri from $F=3$. 4.88 of Ref. 1. Two situatioris ere presented: in Fig. 23 (a) is showr the reduction in iife as a function of ductility redurtion during the if fetine ot the part. For example, it is seen that it the ductility at the end of the intended design life is $50^{2}$ of the iritial ductility, the design life *ill be reduced by 25 to $30 \%$, depending on whether the exponert in the life relation is 0.5 (i.e. typical of the po iffe), or o.s (typical of the co iffe). figure 23(t)* shows anotner way of represeriting the effect. it shows the required reduction in strainrange to naintain : fe at design vaije. Thus, for example, if the ductility at the end of the design life is half of the initial ductility, the initial design life can be maintainsd if the strain is reduced to about $2 / 3$ the design vaiue basad on no juctility jegraciction. due to environeritai effects.

ir the present study we carried out the ducis? ity calculatiors to include what wou?, happen if the decay was exponentizi. A briff descripticn of the procedure is obinged in Afpencix A. The calcuiations are sumarized ir. Figs. 24 and 2E. Figure 24 shiows the hypothesized cuitility desay curves, identified $b^{\prime}$ "half-life" l.e. the time required for ductilitu to decay tu nalf its initiai value. This type of ductility degradation is not typical: it is more corror for ductility to remin fairly constent in tive

*This figure differs from that of Ref. 1, correcting fo: a typographira? error, and minor numerical discrepancies. 
early period of exposire, and to drop off only after some undesirable precipitates have had \& shance to develop. Figure 25 shows the predicted life based or exponential decay vs the desi zn $^{\prime}$ ife based on constant ductility, using the two characteristic exponents assoriated with the wiversalized Strainrange Fartitioning ife relations (i.e., 0.6 to typify pp strain, and 0.8 to typify the others). It is ceen that the results are relatively insensitive to the valle of the exponint, singesting that the curves would apply to all colinations of straitraige components found in specific probises (provided, if course, the assueftion is made that if ductiiity losses occur, trese iosses are applicable to both plastic deformation as well as creep). Note, however, that drastic reductions in life are possible if losses of ductility are hig. enouth. For example, a design life of 30 years can become a semice life of $j-4$ years if the ductjlity half-izfe is one year. This, of course, is not expected for zateriais actualiy used in reactors, jut it indicates how importait it is to assure that jrastic losses of ductility be aroicied.

\section{SUMARY AND COACLIIDING REMARKS}

In this report we have $a:$ tompted to outiine a simple procedure for treating creep-fatigue for low strairiranges and long hold times. We have suggested that a semi-experimental approach, wherein several cycles of the imposed loading is actually applied to a specimen in ord.r to deteraine the stable nysteresis loop. can be very usefui in the ana?ysis. Since such tests require on' $f$ a small fraction of the totai failure tine, they are not inierently ponhibitive if experimental equipment is available. It is: in fact, a simple thod of by-passing the need for accurite constitutive equations since the material itself acts to translate the ieposed loading into the respcis ive hysteresis loops. When Strainrange Partitioning has been applied in such cases very good results have been obtained.

Since in many casys a concomitant experimental program is impractical, a simple procesure is outlined for handling the problem entirely by 
analysis. Some Epproximations are involved, of cours?, which require further checking. Calculations shown include continuous cycling, sensile holds, compressive holds, and symetrical tensile/compressive holds. Constani strain-range curves of cycies to failure vs hold ti display the fasiliar tendency to saturate at both very short and iong hoid times, with an S-sinaped pattern over a iarge range of toid times. Similariy, constant frequency curves of strainrange vs cycles to failure are of a faniliar shape, jaing asymitotic to two straignt lines on logarithmic coorcinates like the sii. of an elastic and an inelastic component. Each fanily of lines shows the characteristic increases in siope as holc time is increased, a feature observed in the shorter time range by several investigators. While these figures are fresented merely is sampie results af a caiculation prucedure, rather than accurate predictions, they may serve as guides to the selection of critical experiments to comare predictions of SPF with alternative methods.

Oxidation effects are not directly included in the computations, except that the constants invoived in the caiclilations are obtained in the environment of interest. Although iong term exposure can be exfected to accentuate tha oxidation, or to promote detaliurgical precipitation that can seriousiy affect fatigue iffe oy influencing rechanicai froperities suit. as strength, toughness, and ductility, these factors were r.st inciuded in the calculations. The SRP frawework does, however, aliow for incilision of such effects if they are known or expected to occur. Cinapter 4 of Rer. 1 first siggested how sich caicuiations iligh be carried out. It should also te pointed out, howeve ${ }^{-}$, that in several analyses where $i t$ has been possible to make comparisons, the degree of predictability by the SRP afproach of long-time results is iittle different from that of shcrt-time results. Figure 21 suggests. for example, that extrapolations bj a time faccor of 10 to 50 may be reassnabie. This concilision! must, of course, Se extensively checked before confidence can be estabiished. However, it would scen reasonable :c assum: that if extrapolations are to be rade to the 30 year range, then the 1 ife and crepp rate relations should be aeternined fros tests lasting $i$ to 3 years, an attainable requirenent. 
We have also extended in this report the applization of Sirainrange Partitioning to the treatment of probiems involving progressive loss cf ductility due to enviromental exposure. In addition to the previcus arilysis of Chapt. 4 of Ref. I wherein linear reduction ir ductility with: time was treated, we have extended in tnis report the treatment of ductiliity variations to include the case of exponential loss with ine. This is an extrese case, not exptected in service, but it illustrates the importance cf choosing stable materials that do not suffer drastic iosses in ductility during their early exposure.

\section{ACXMONLERSEMENT}

In additiz to subcontract support fros Oak Ridge National Labonatory, this research was supported, in part, by a grant from the WASA Lewis Research. Center (M. H. Hirschbers, Trant Monitor). 


\section{REFERENCES}

i. Carden, A.E., Coffin, L.F., Manson, S. S., Severud, !..K., Greenstreet, W.C., "Time-Lependent Fatigue of Structural Alloys", URNL-5073, 1977 .

2. Halford, G.R., Hirschberg, M.H.. Manson, S.S., Temperature Effects on the Strainrange Partitioning Approach for Creep-Fatigue Analysis", Fatigue At Elevated Temperatures, STP-529, ASTM, 1973.

3. Manson, S.S., Halford, G.R., and Hirschberg, M.H., "Creep-Fatigue Analysis by Strainrange Partitioning", Proceedings of First Symposium on Design for Ele:ated Temperature Environment, San Francisco, California, May 10-12, 1971, pp. 12-24; disc. Pp. 25-28 (1971):

4. Conway, J.B., Stentz, R.H., and Berling, J.T., "Fatigue, Tensile, and Relaxation Behavior of Strainless Steeis", United States Atomic Energy Comission, 1975.

5. Manson, S.S., Halford, G.R., Nachtigal, A.J., "Separation of the Strain component "or Use in Strain Rarige Partition irig", published in Advances in Design for Elevated Temperature Environment, ASME, 1975.

6. Sheffler, K.D. . Doble, G.S., "Influence of Creep Damage on the Low-Cycle Thermal-Mechanical Fatique Behavior of Two Tantalur: Base Alloys", NASA-CR-121001, May $10 \% 2$.

7. Shefiler, K.D., "Vacuum Thermal-Mechanica! Fatigue Testing of Two Iron Sase High Temperature Alloys", NAS CR-134524, TRW ER 7697, NASA TO; ical Report $¥ 3$, (January 1974).

8. Kortovich, C.S., "Ultrahigh Vacuum, High Temperature, Low Cycle Fa iigue of Coated and uncoated Rene' 30", NASA Report NAS CF-135003, TRW ER-7861, (ApriT 1976).

9. Saltsman, J.F., Hal cord, G.R., "Application of Strainrange Partitioning to the Prediction of MPC Creep-Fatigue Data for 23 Cr-iMo Steel", NASA Report TM X-73474, December 1976.

10. Curran, R.M., Wundt, B.M., "Continuatior. of a Stu'y of Low-Cyc'e Fatisue and Cieep Interaction in Steels at Elevated Temperatures", MPC-ASME Sympusium oni Creep-Fatigue Interaction, December 1976.

11. Mansor, S.S., "The Chalienge tn Unify Treatment of High-Temperature Fatigue a Partisan Propcsai Based on St:ainrange Particioning ASTM-ASNE, STP 5201973. 
BLANK PAGE 


\section{Appendix $\dot{A}$}

The ductility equation which is a function of time(t) is

$$
\begin{aligned}
& \qquad D_{t}=D_{0} e^{-a t} \\
& D_{t}=\text { Ductility }-t \text { years } \\
& D_{0}=\text { Original ductility } \\
& a=\text { Constani (function of half-life) } \\
& t=\text { time (years) }
\end{aligned}
$$

The strain equation is

$$
\frac{\Delta E}{D_{t}}=\Delta i^{-a}
$$

Solve for $N$ (number of cycles)

$$
N=\left[\frac{A D_{0} e^{-a t}}{A s}\right]^{\frac{1}{a}}
$$

Damage equation is

$$
\int_{0}^{y} \frac{4 D_{0} e^{-3 t^{-}-\frac{1}{\alpha}}}{\Delta \varepsilon} n d t=1
$$

$$
\begin{aligned}
n & =\text { Number of cycles, per year } \\
x, A & =\text { Constants of materiai } \\
\Delta \varepsilon & =\text { Strain Range } \\
y & =\text { Years to failure if ductility decreases }
\end{aligned}
$$

Integrate and substitute limits. 


$$
\frac{A D_{0}}{\Delta \varepsilon}{ }^{-\frac{1}{\bar{s}}} \frac{n \alpha}{a} e^{\frac{a}{\alpha} y}-1=1
$$

Eq. (1)

Let $\quad H_{0}=\left[\frac{A D_{0}}{L \varepsilon}\right]^{(1 / \alpha)}$

Eq. (2)

be the number of cycles if roo change in ductiitity occurs. Substitute equation (2) into equation (1) and solve for $y$.

$$
y=\frac{a}{a} \ln \left(\frac{a}{a} \frac{N_{0}}{n}+1\right)
$$

Also

$$
N_{0}=n y_{0}
$$

$$
\begin{aligned}
n= & \text { number of cycles per year } \\
y_{0}= & \text { number of years to failure if there is no decrease } \\
& \text { in ductility }
\end{aligned}
$$

Therefore

$$
y=\frac{\alpha}{a} \ln \left(\frac{a}{\alpha} y_{0}+1\right)
$$




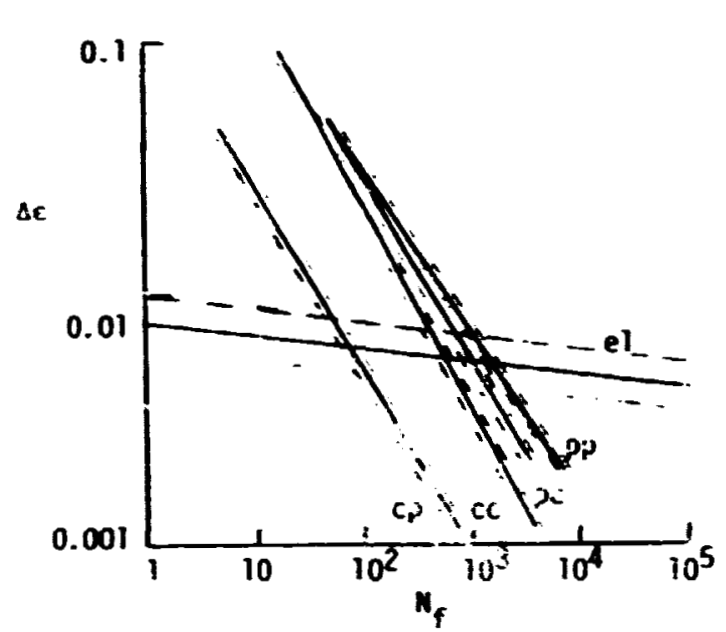

a) Partitioned Strainrange Life Relations

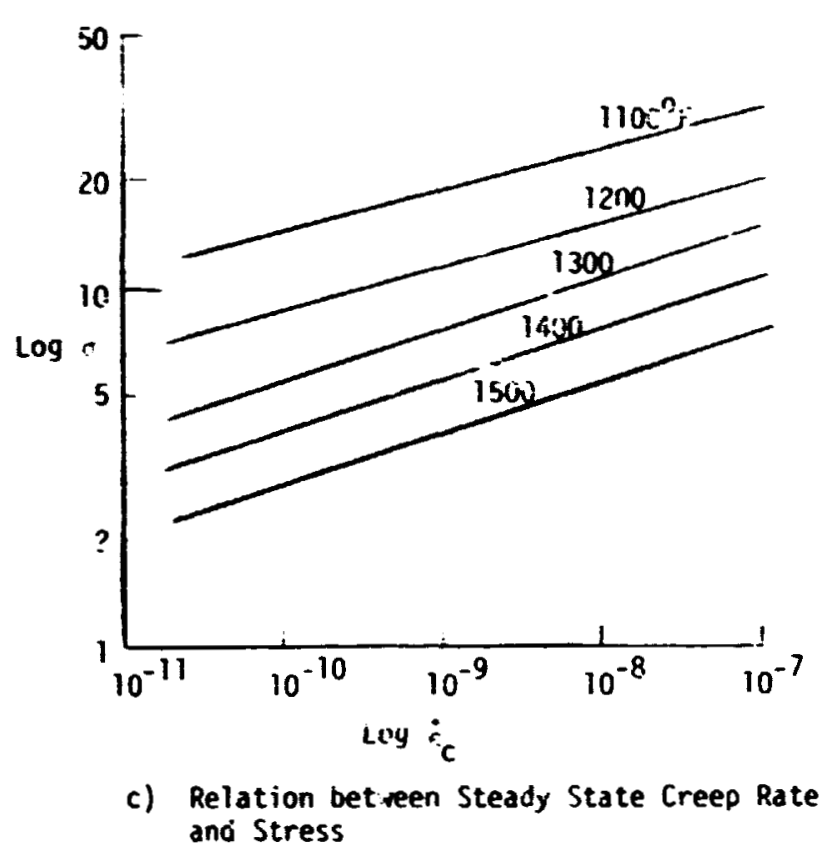

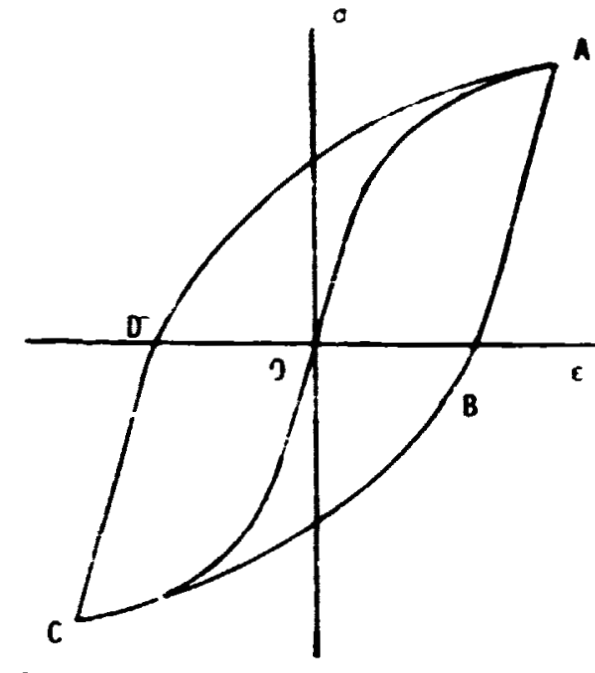

b) Cyclic stres:-strain cur.e and Hysteresis !.sop for Rapid Cycling obtained by Principle of Double Anplitude Construction

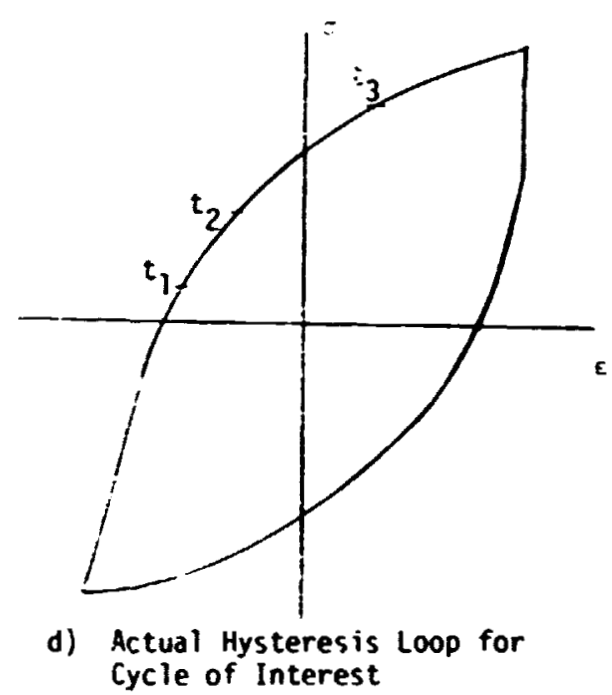

Fig. 1. Desired Input Information for Treating Creep-Fatigle by Strainrange Partitioning 

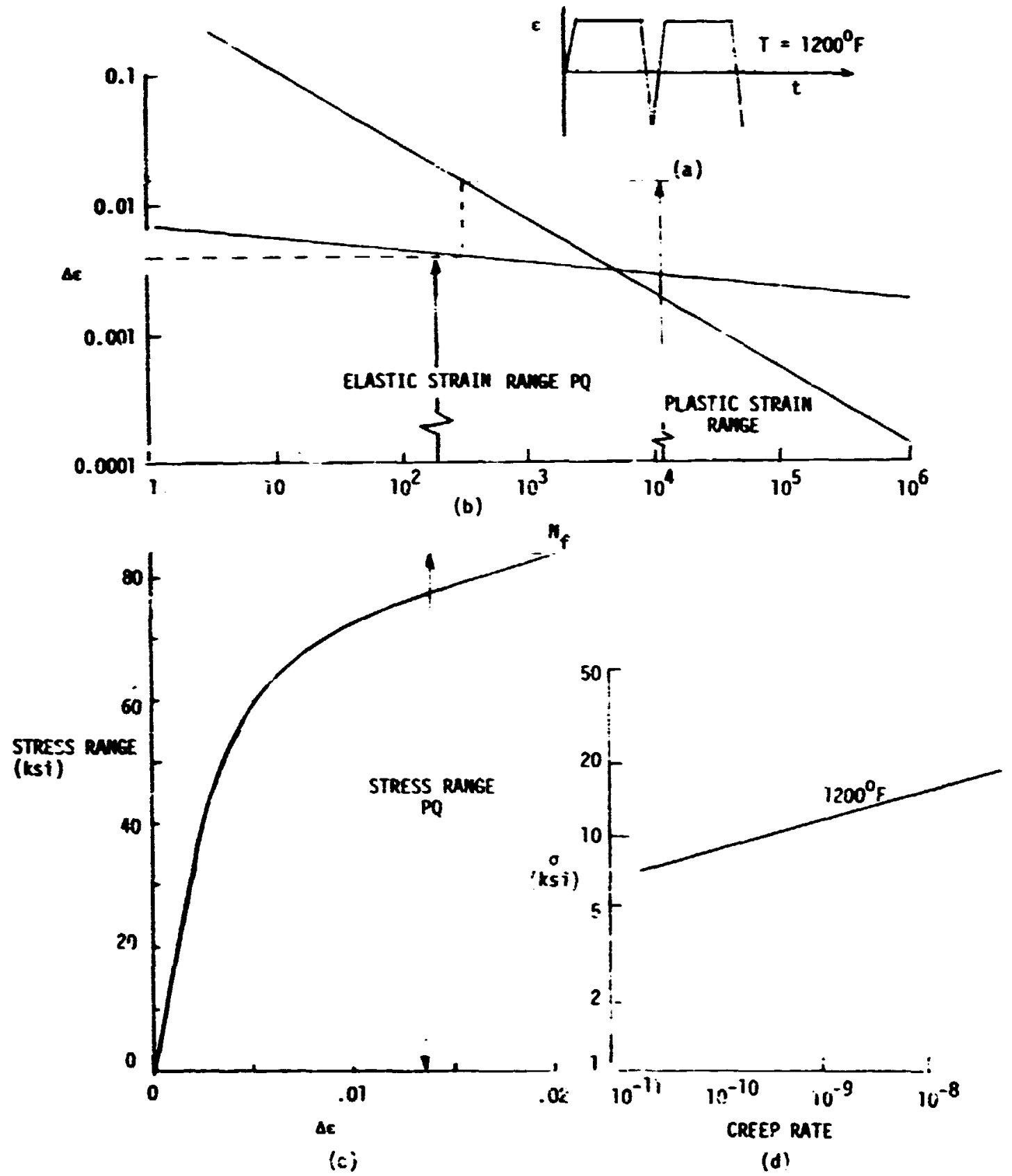

Fig. 2. Input information for analysis of hold-time cest. 

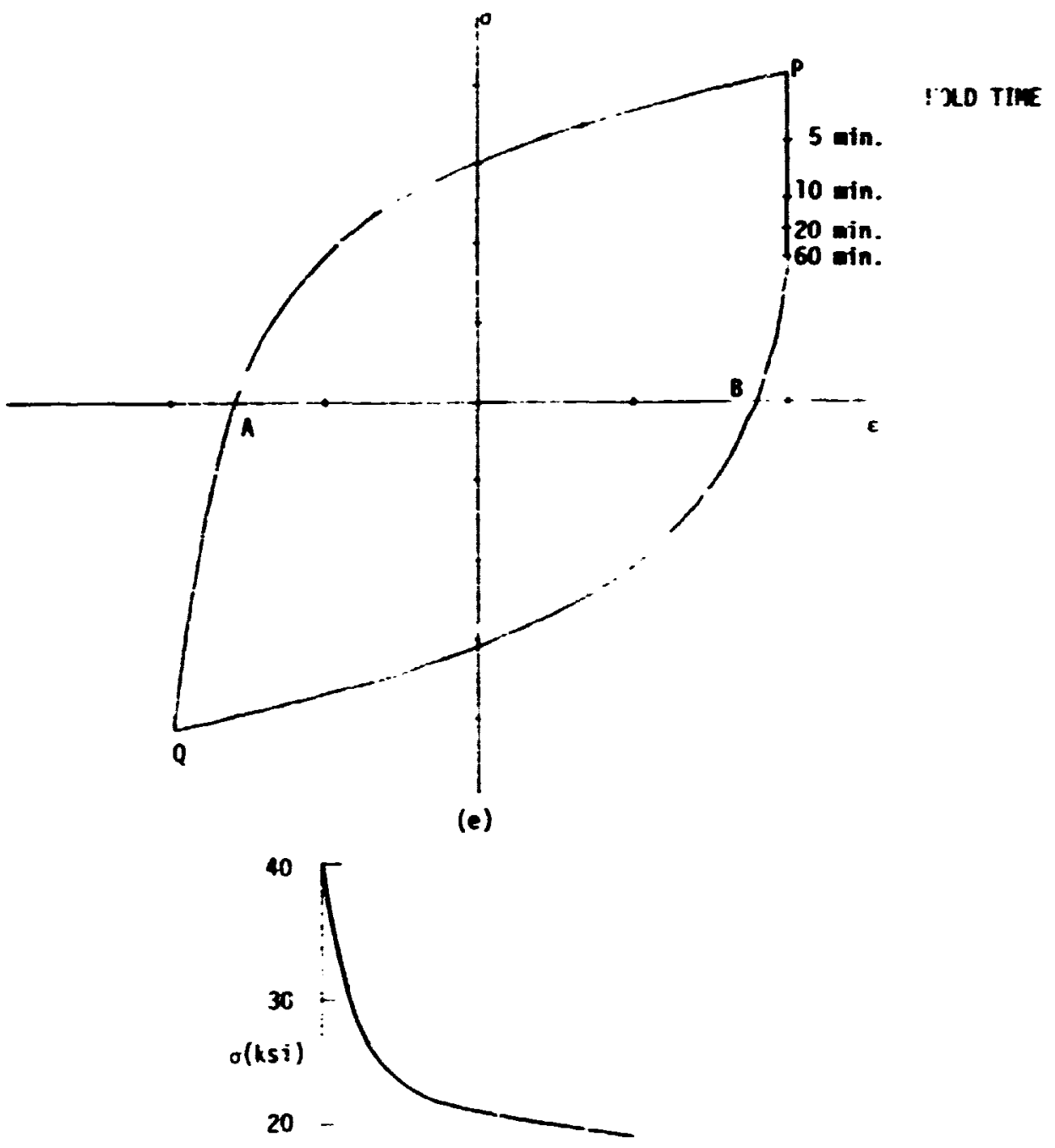

10

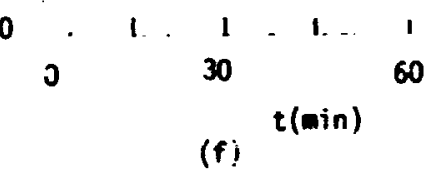

Fig. 2 (cont.) 


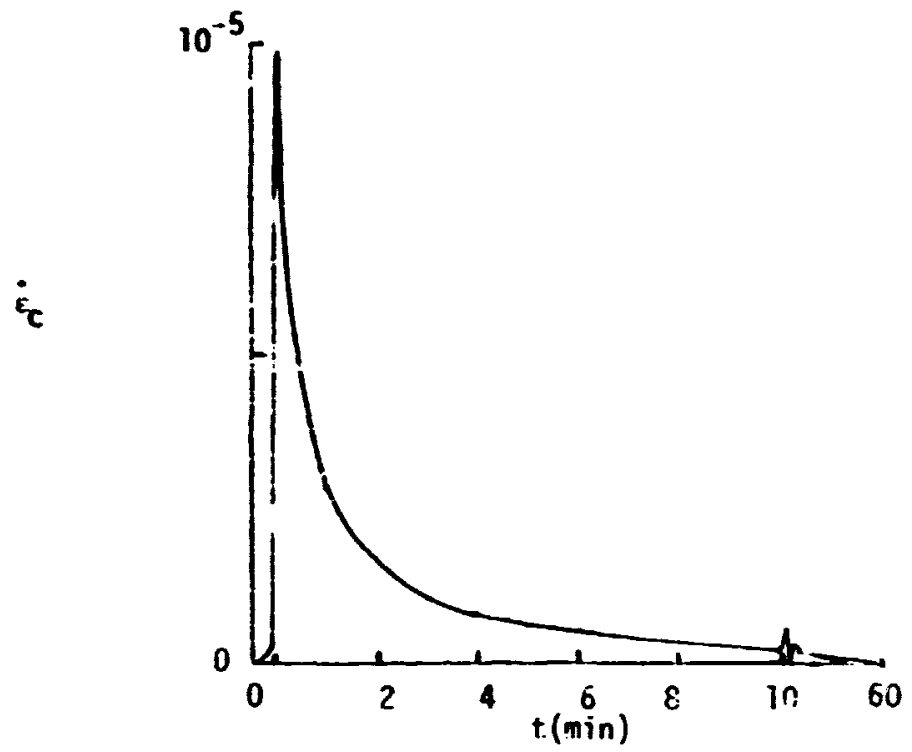

a) Tensile sciondary crzep $=$ area under creep rate curve $\left(0.75 \times 10^{-4}\right)$

E?astic stress range $=83.74 \mathrm{ksi}$

b) Elistic strainrange $=\frac{83.740}{21.1 \times 10^{\epsilon}}=3.96 \times 10^{-3}$

Erom fig. 2(b) Plastic strairrange $=1.60 \times i 0^{-2}$

c) From Fig. 2(e), total inelastic strainrange $=A B=1.67 \times 10^{-2}$

d) Vansient creep strainrange $=$ tocal inelastic strainrange - plastis strainrange

$$
=1.67 \times 10^{-2}-1.60 \times 10^{-2}=7 \times 10^{-4}
$$

e) To" tersile "creep" for SRP purposes

$$
\begin{aligned}
& =\text { tensile seconfary creep }+0.1 \times \text { transient creep } \\
& =9.75 \times 10^{-4}+0.1\left(7 \times 10^{-4}\right)=i .045 \times 10^{-3}
\end{aligned}
$$

f) Total compressive creep for SRP purposes $=0$

g) $\Delta \varepsilon_{c c}=0$

h) $\Delta \varepsilon_{c p}=1.045 \times 10^{-3}$

i) $\Delta \varepsilon_{p p}=$ Total inelastic strainrange minus $\Delta \varepsilon_{c p}=1.5655 \times 10^{-2}$

j) Trus $F_{p p}=.9374 \quad F_{C p}=.0626$

k) Ising Interaction iamage Rule $\frac{.0626}{26}+\frac{.9374}{233}=\frac{1}{N_{f}} \quad N_{f}=155$

rig. 3. Mericai Analysis of Strain-hold Problem. 


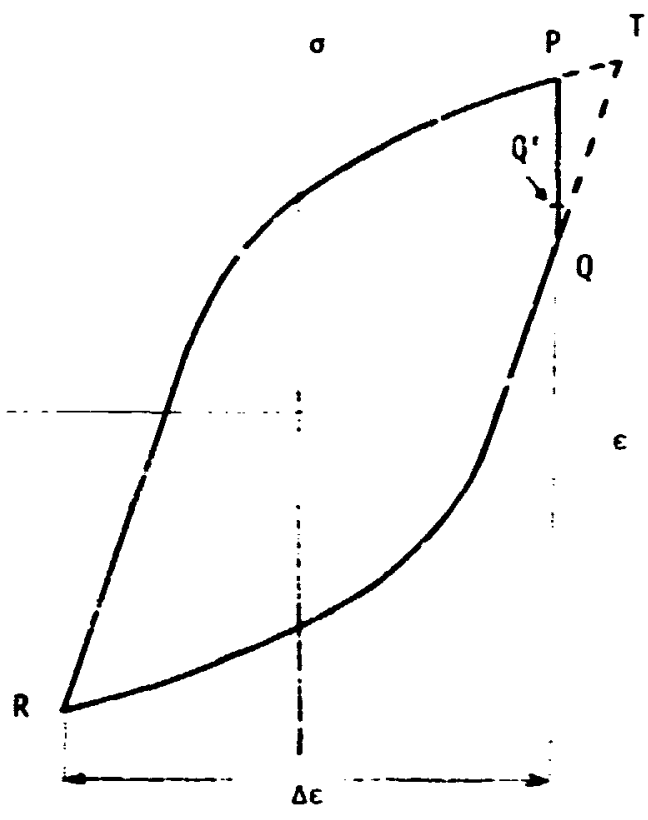

(a)

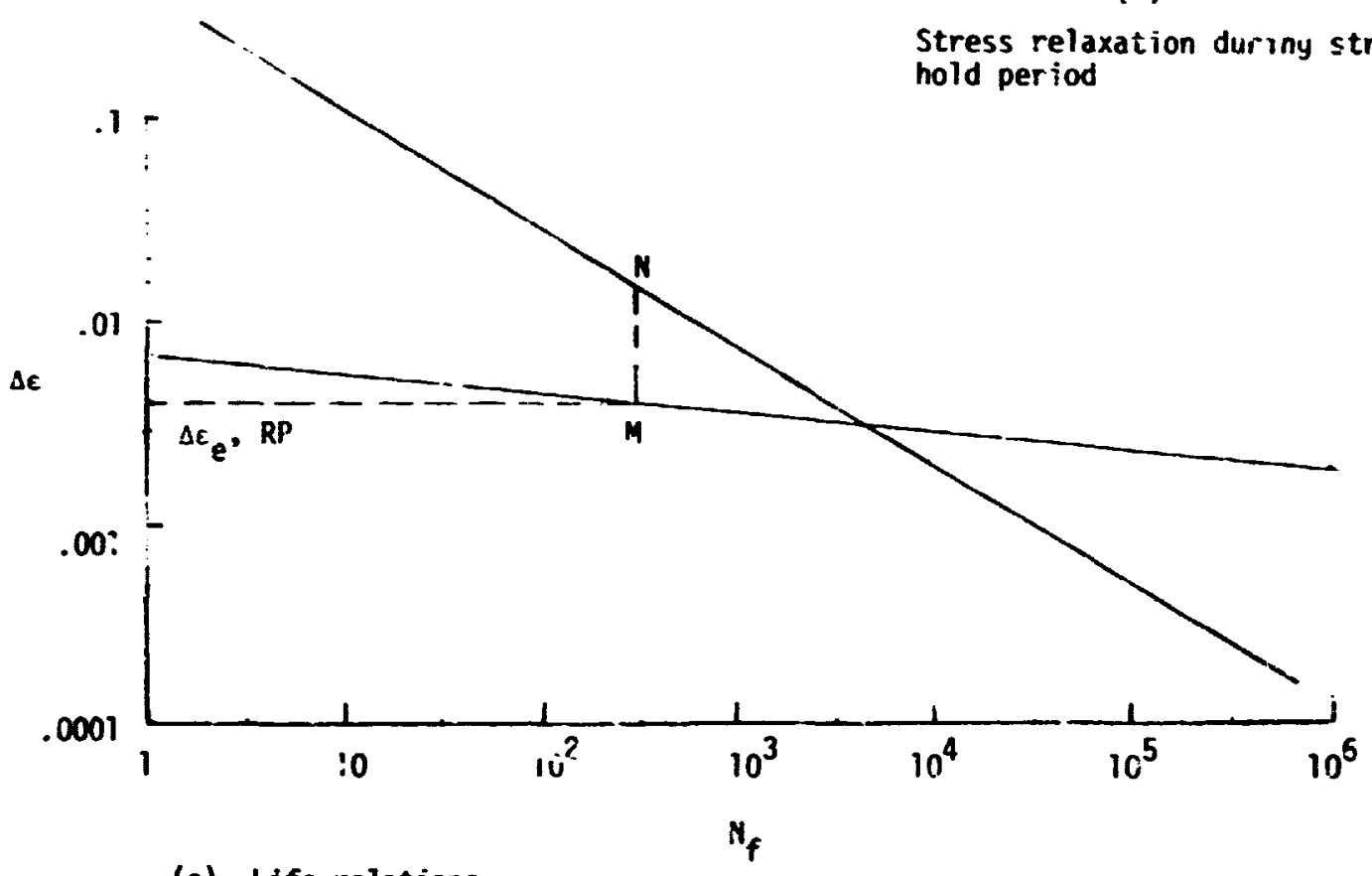

(c) Life relations

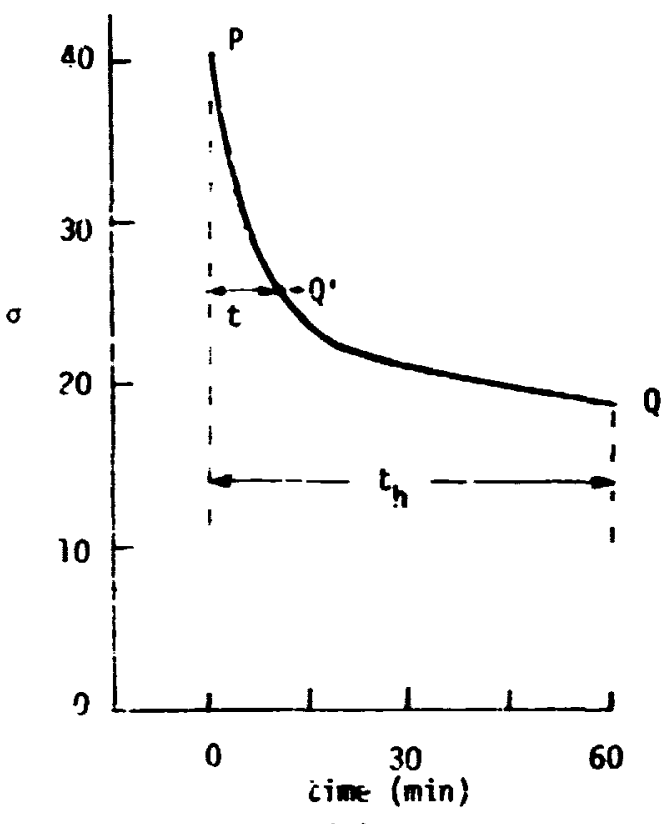

(b)

Stress relaxation duriny strain hold period

Fig. 4. Analysis of rensile-hold problem by engineering estimation of hysteresis loop. 


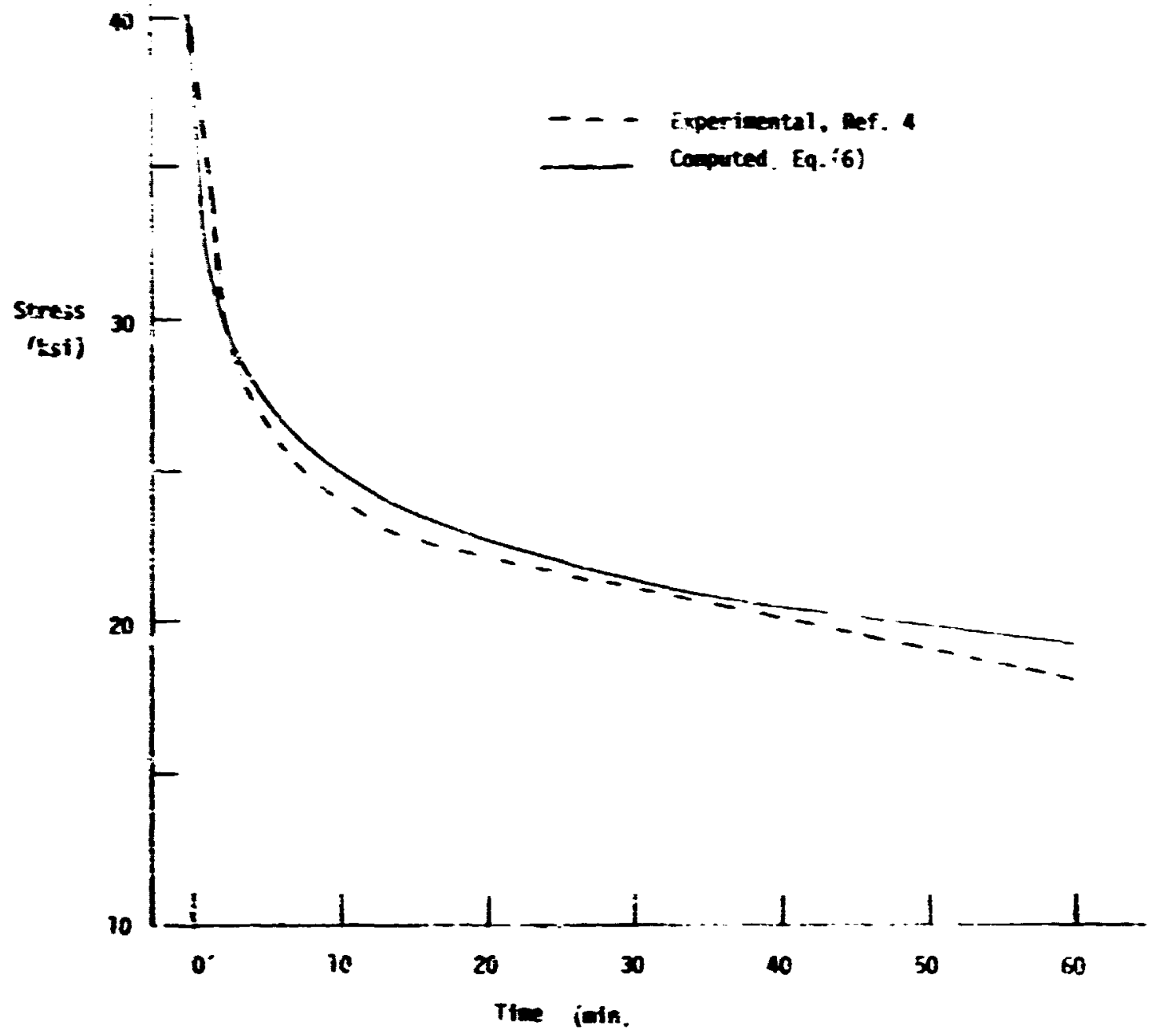

Fig. 5. Cosparison with experisentai shservition of stress relaxsition determined fron paver-10u equntion betwen stress and secondary crent rate. 


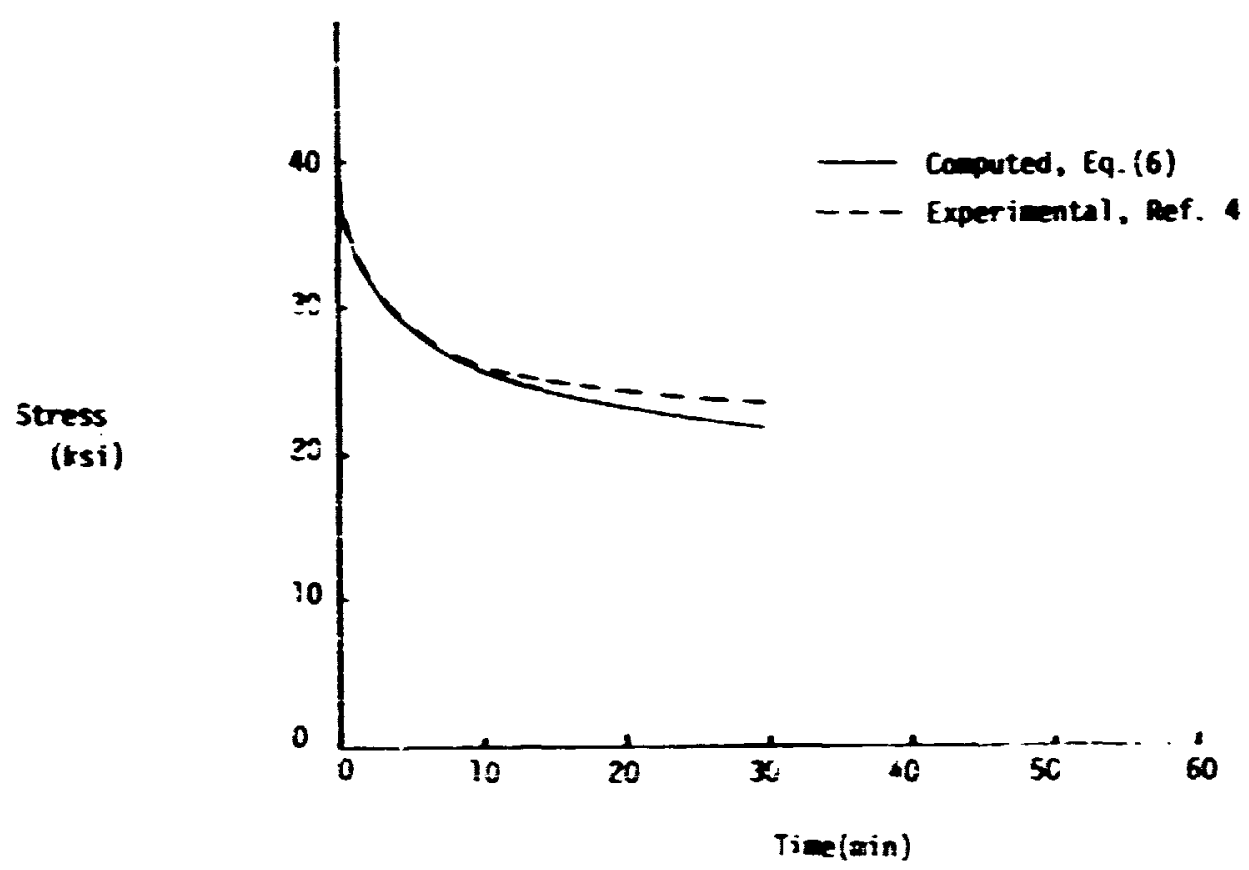

Fig. 5. (b)

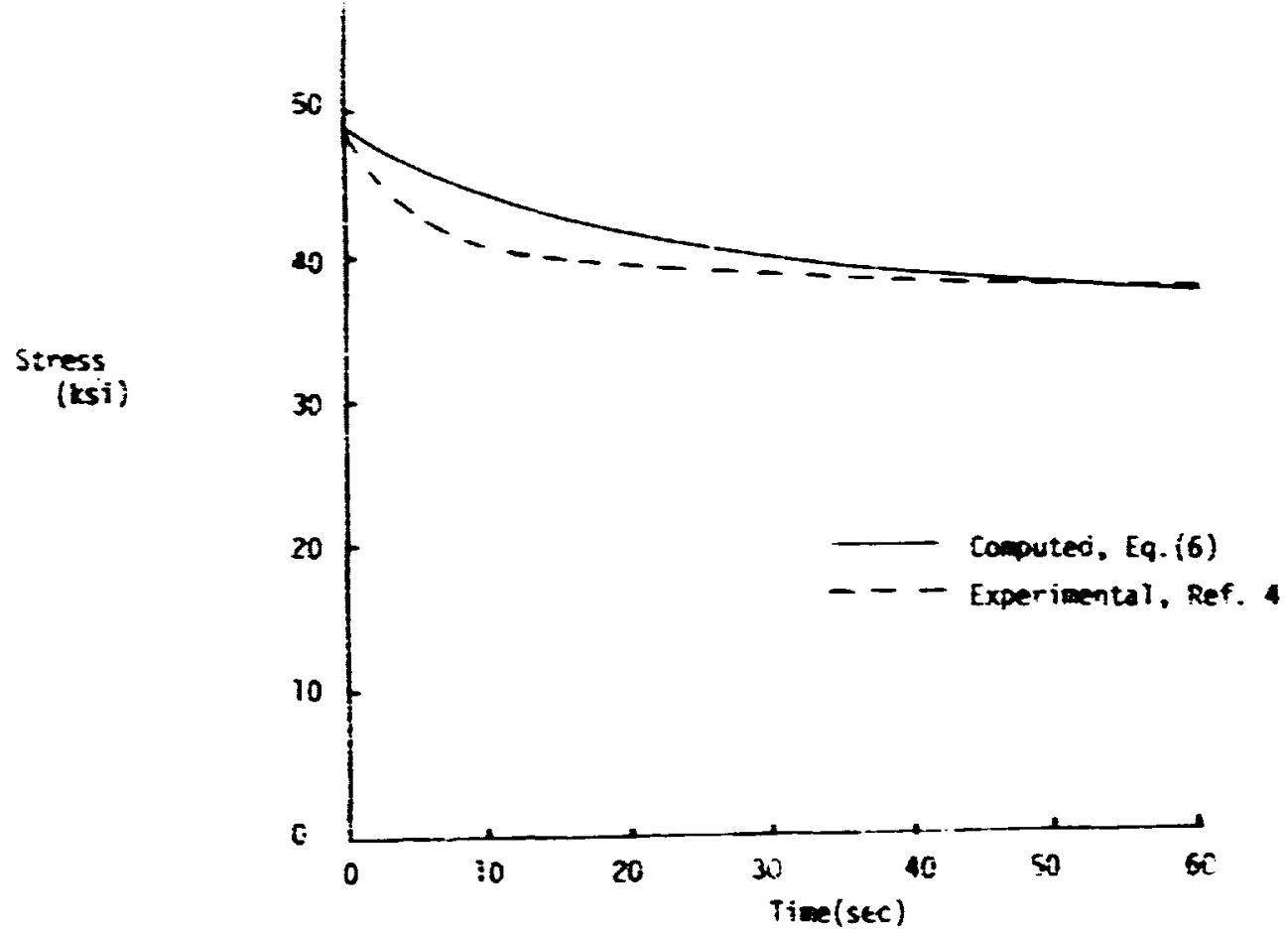

fig. 5. $i=$ ? 


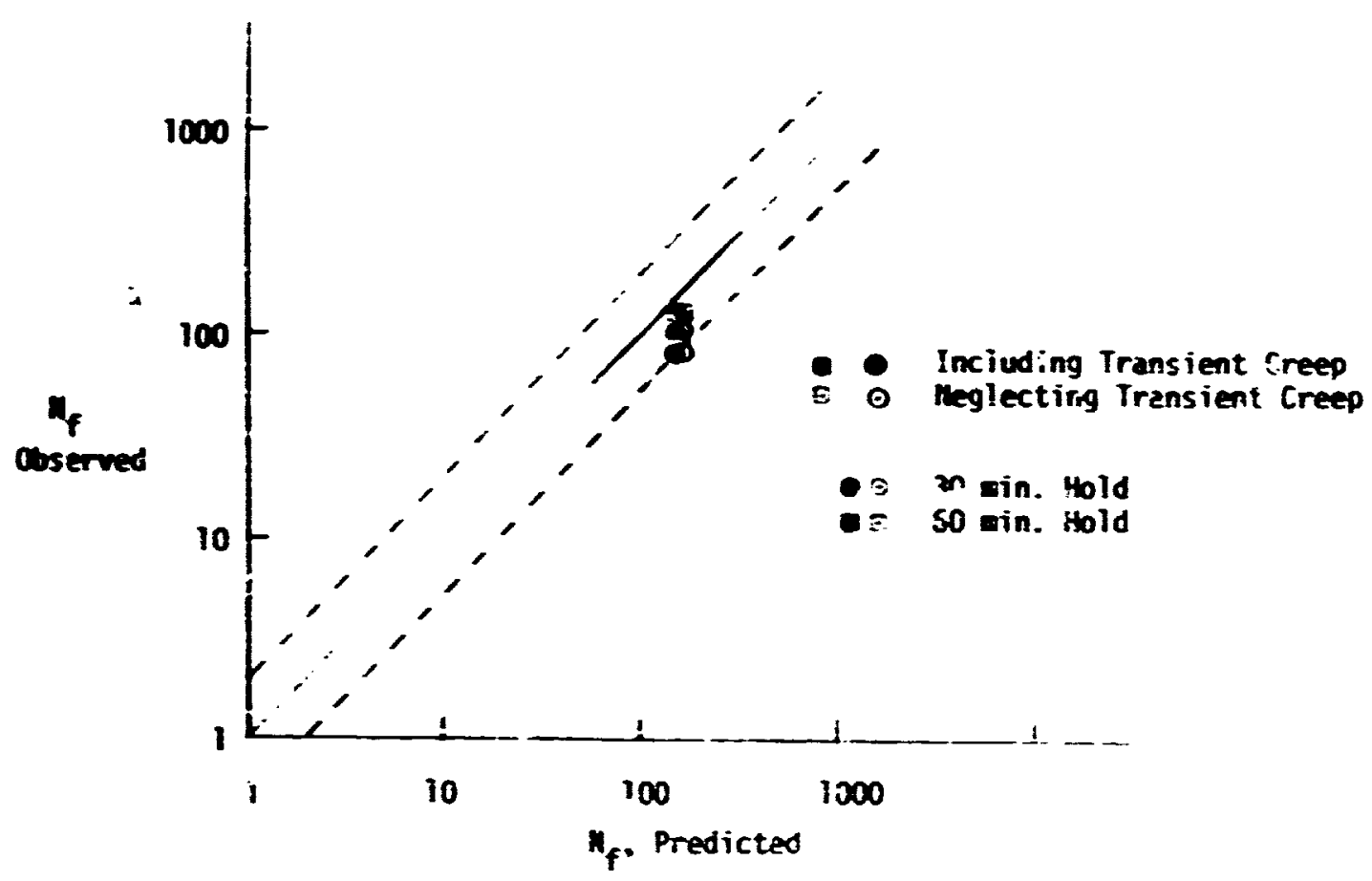

(a) Comparison of predicted and coserved iife vaiues for high-strain tensile hold tests.

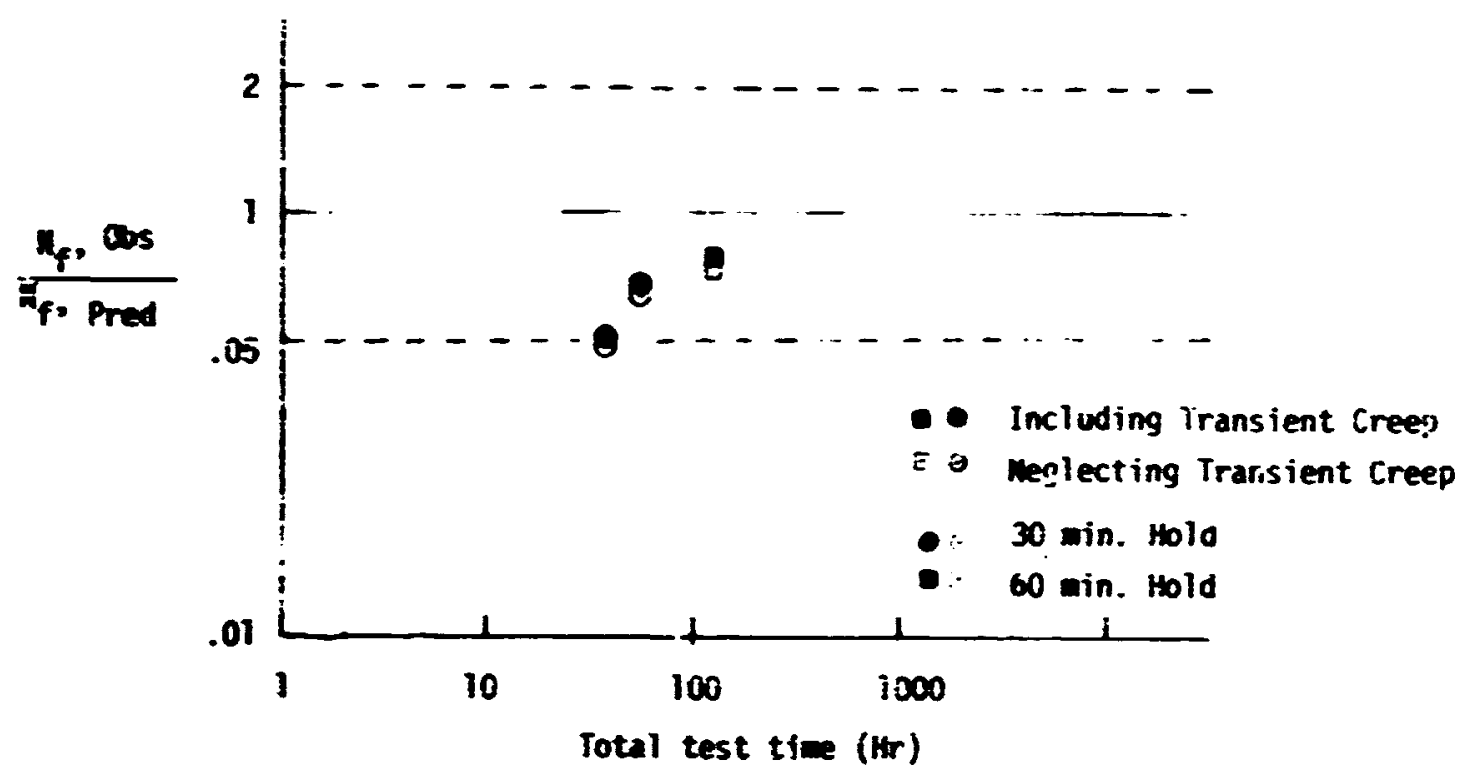

Fig. 6. Correlation of observed and predicted lives in tensile nold relaxation tests. 


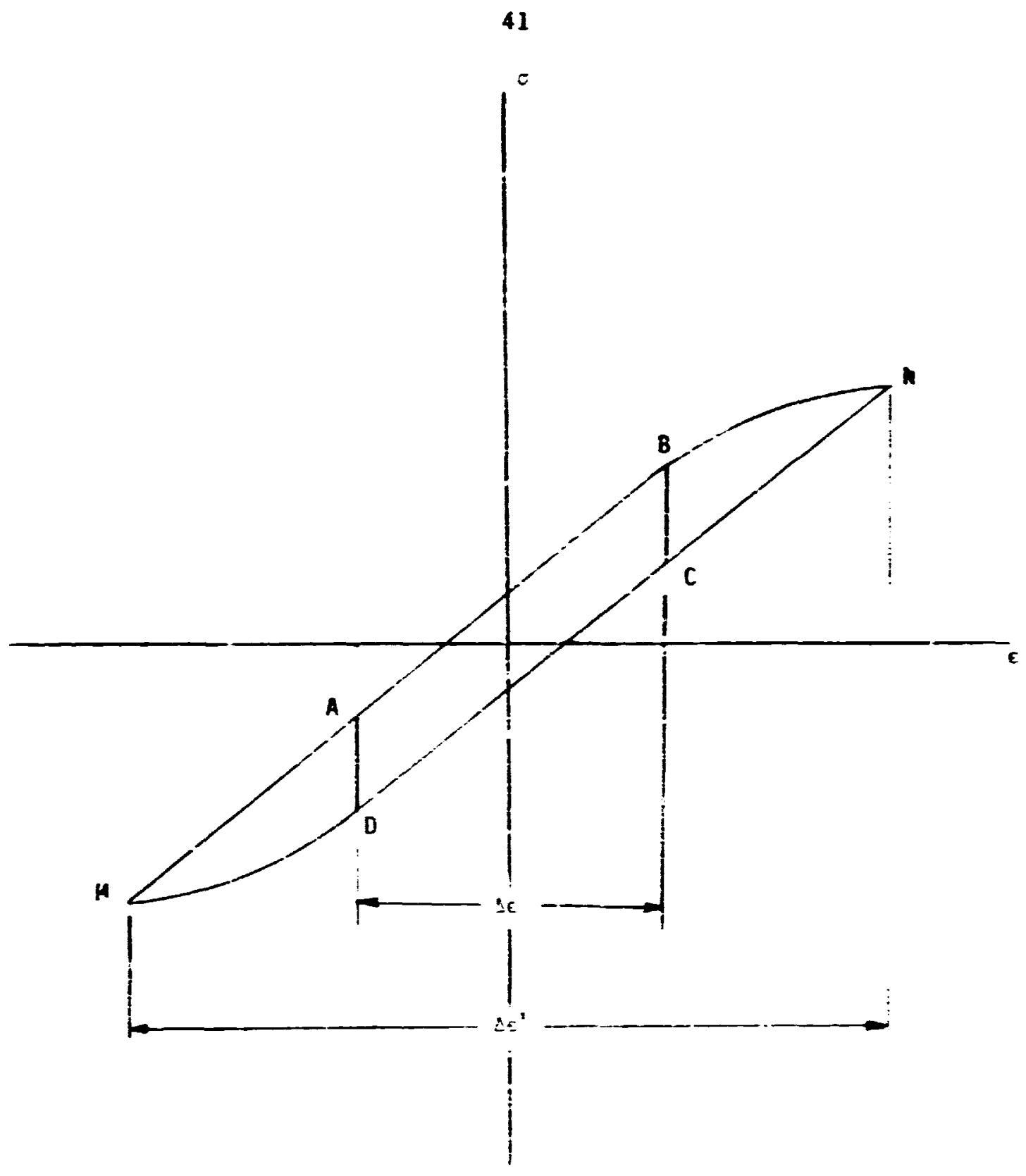

Fig. 7. Construction to simpiffy analyses of symmetrical hold tests. 


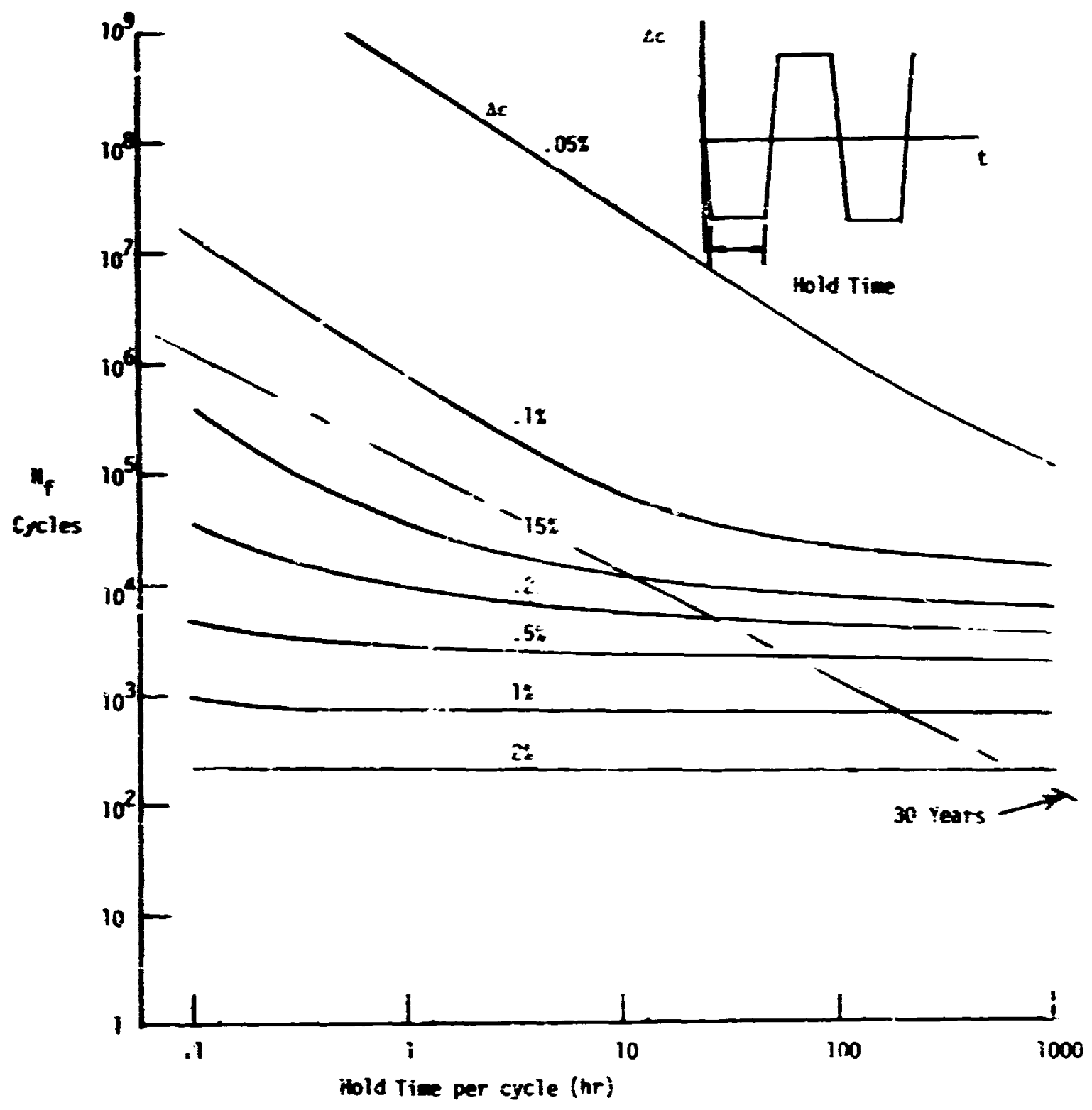

Fis. 8. Life relations ior low strainranoes and long bold-times with rapid stiain raping for $316 \mathrm{SS}$ it $1300 \mathrm{~F}$, expressed with strainrance as parameter. 


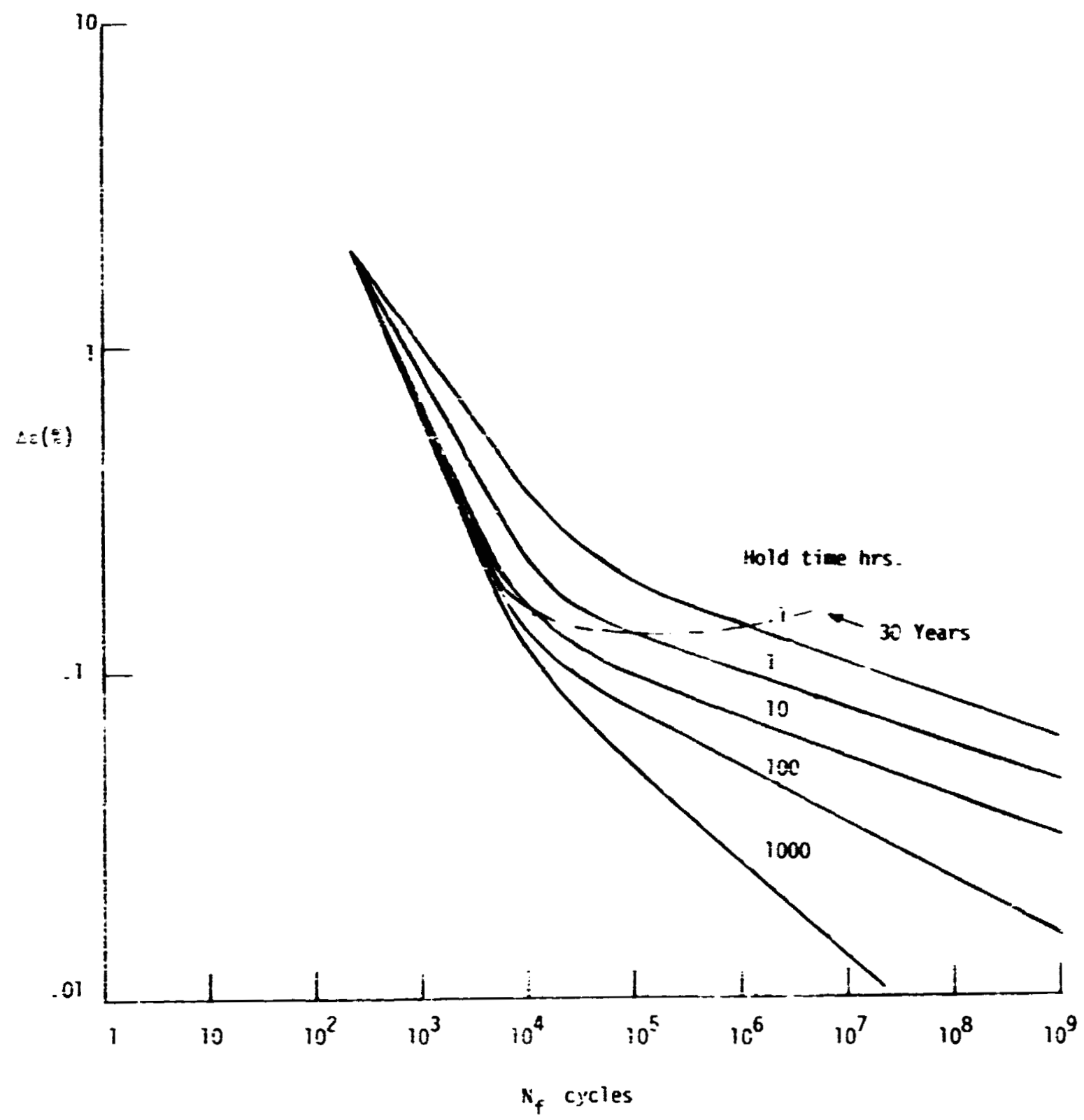

Fig. 9. Life reiations for iow strainrances and long hold times for 316 S5 at 1300 f expressed with hoit timp as parameter. 

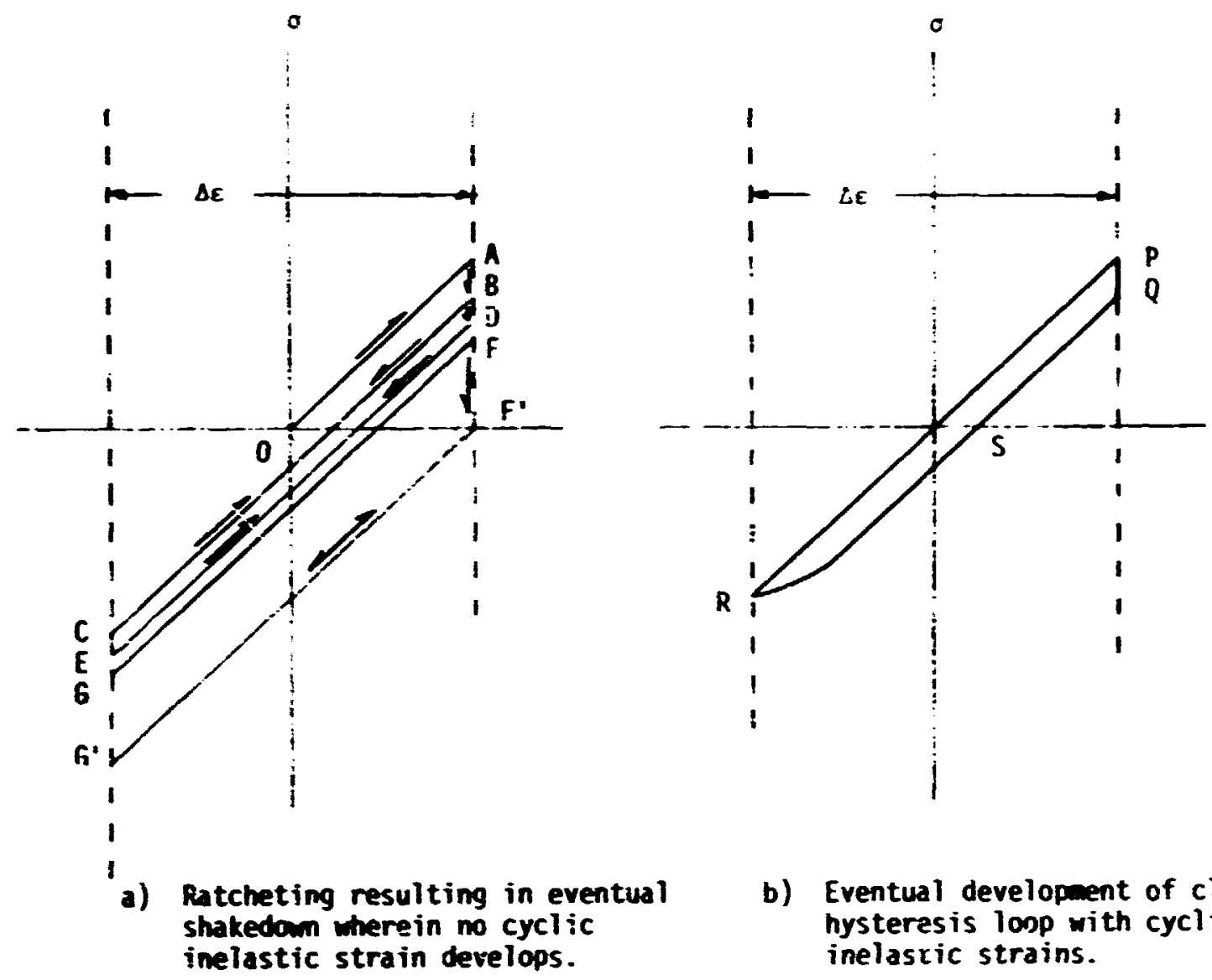

Fig. 10. Two possible extremes of behavior in strain cycling at low strainrange with tensile hold periods. 


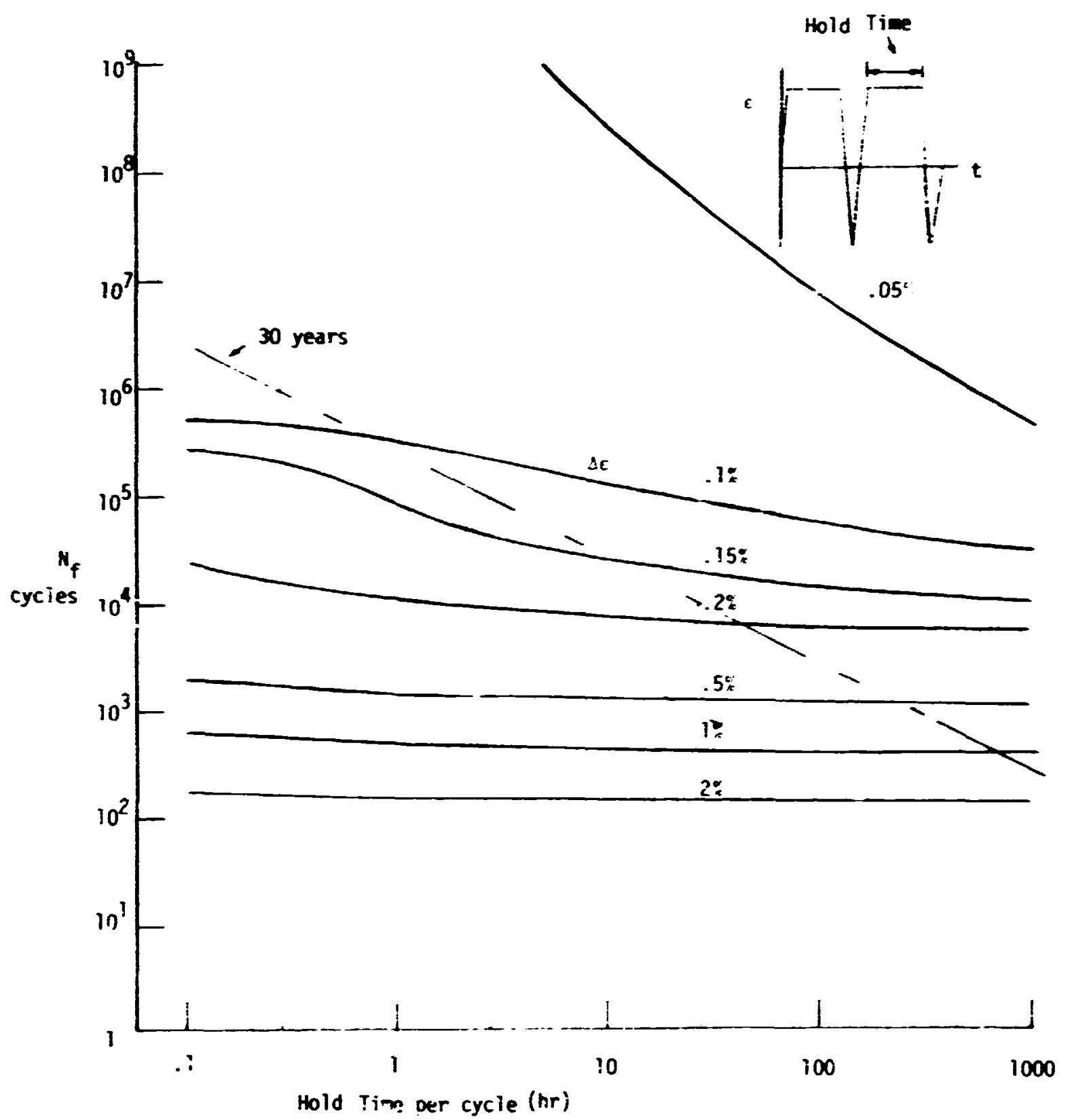

Fig. 11. Life relationships for low strainranges and long hold-times for rapid strain ramping coabined with tensile hold at a maximn strain, 316 stainless steel at 1300 . Curves presented with strainrange as parameter. 


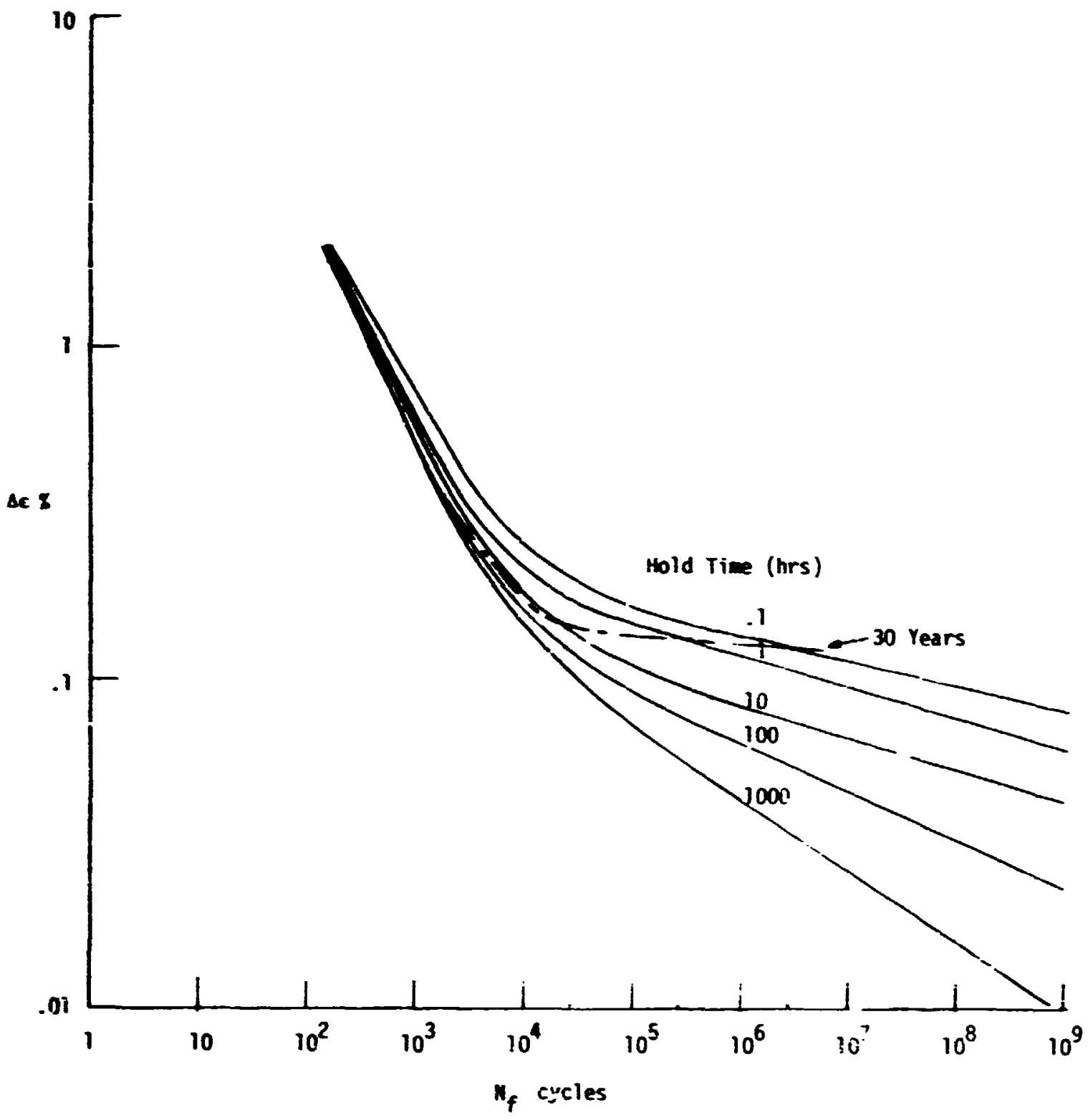

Fig. 12. Life relationships for low strainranges and long hold-tines for rapit strain raping combined with tensile hold at a maxim strain, 316 stainless steel at !300f. Curves presented with hold tive as paraneter. 


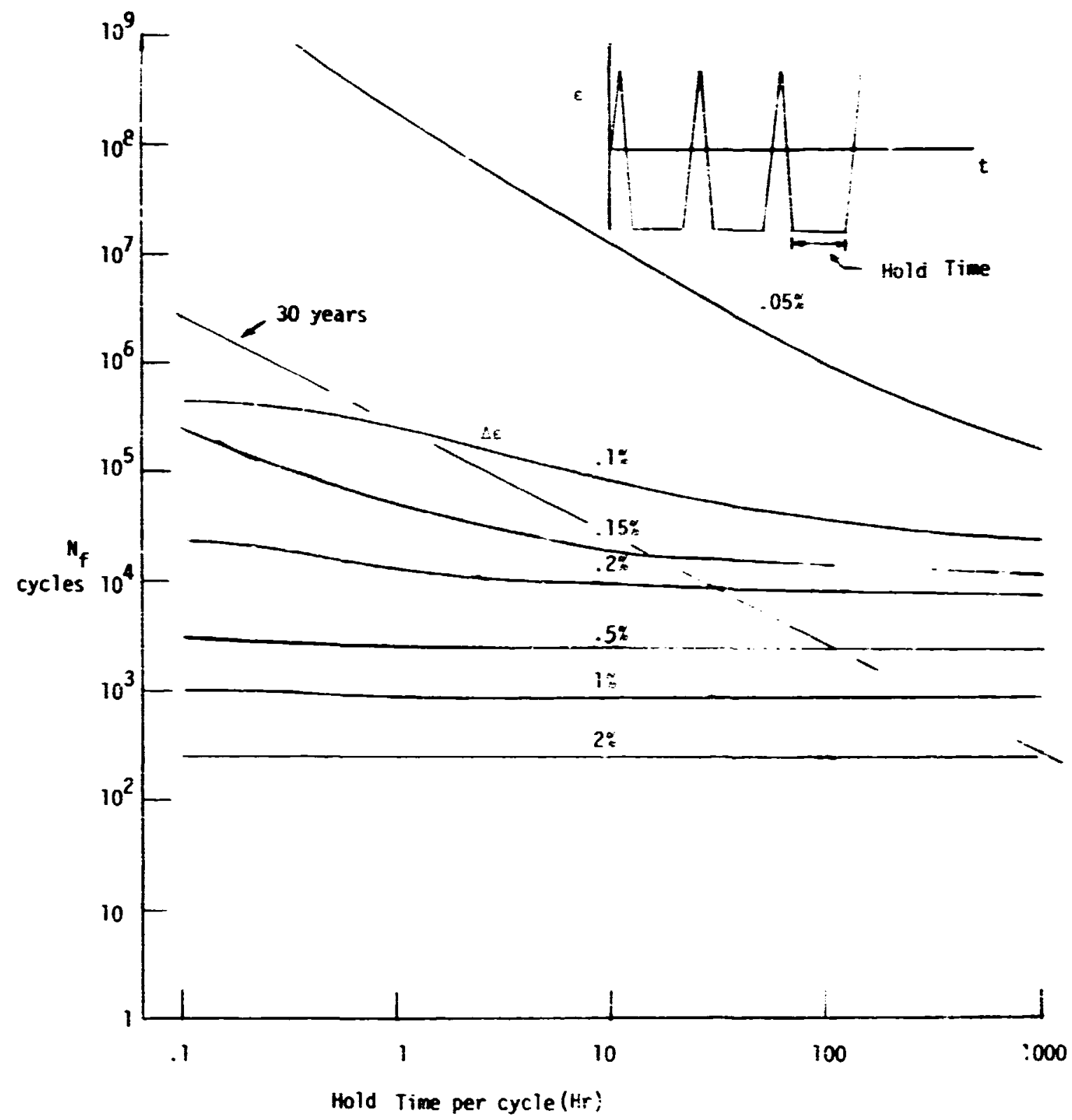

Fig. 13. Life reiationships for low strainranges and long hold times for rapid strain raming combined with compressive hoid at maximus strain, 316 SS at 13.MeF. 


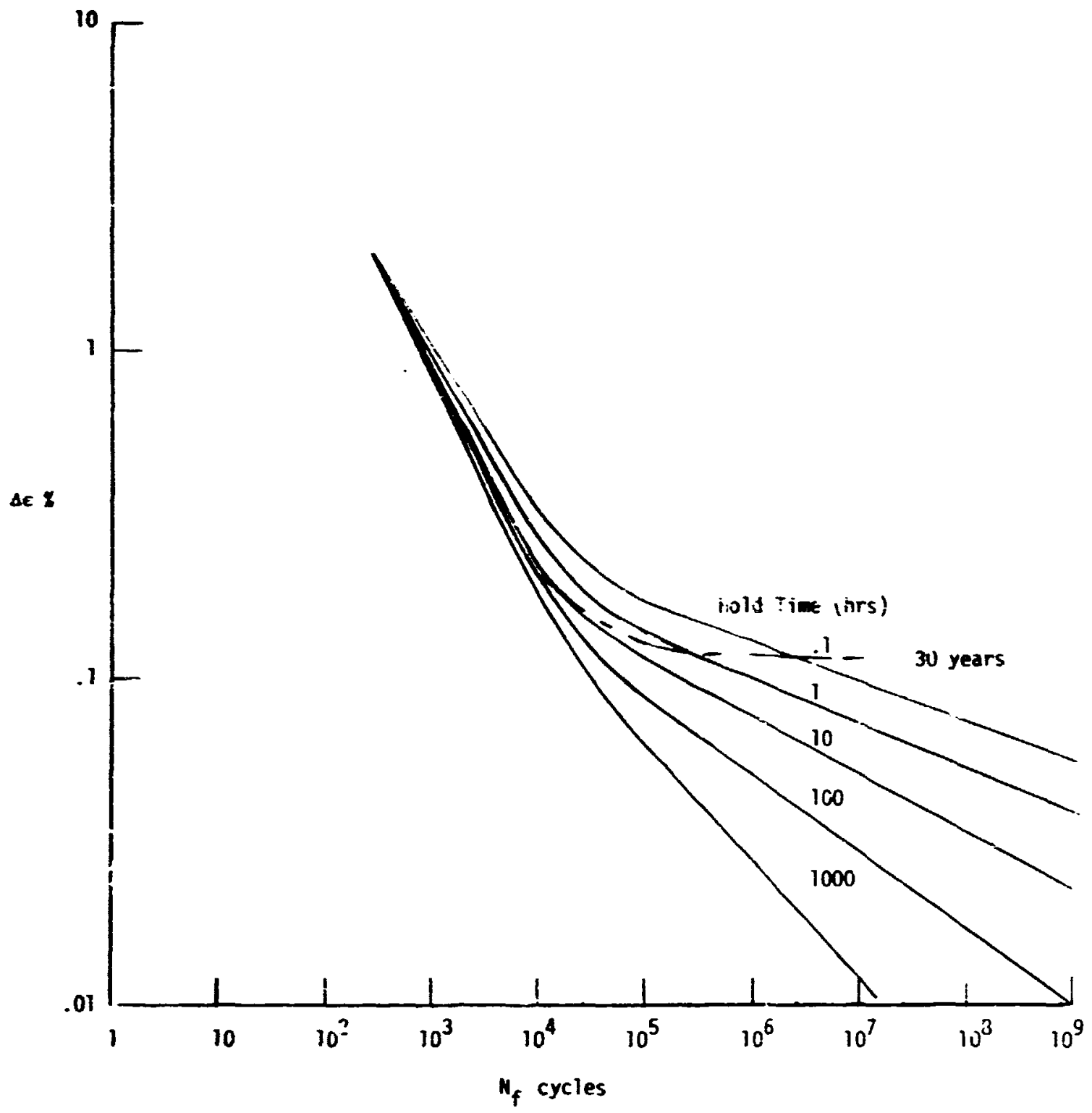

Fig. 14. Life relationships for low strainranges and long hold-times for rapid strain ramping cokbined with compressive hold at a maximum strain, 316 stainless steel at $1300 \mathrm{~F}$. Curves presented with nold-time as parameter. 
c

(a)

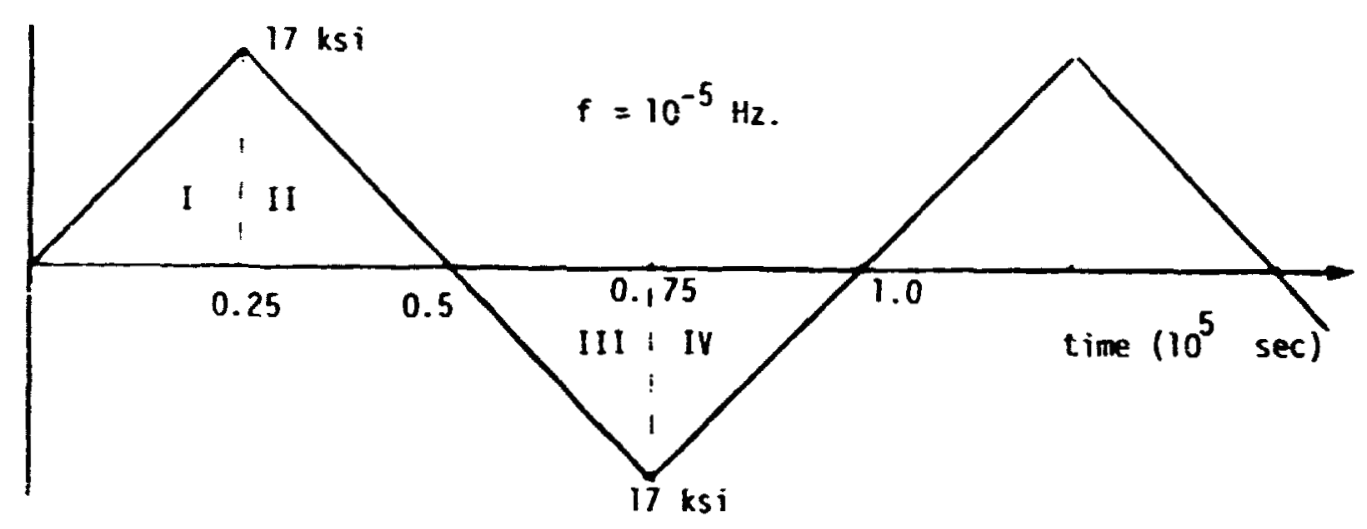

1. For quarter cycle I $\sim=6.8 \times 10^{-4} t$

$t=\sec ., \sigma=k s i$ $\dot{\varepsilon}_{c}=3.63 \times 10^{-16}{ }_{\sigma} 7.14=8.791 \times 10^{-39} \mathrm{t}^{7.14}$.

$\varepsilon_{c}=\int \dot{\varepsilon}_{c} d t=8.791 \times 10^{-39} \int_{0}^{.25 \times 10^{5}} t^{7.14} d t=6.80<\times 10^{-4}$

For tensile half creep strain $=2 \times 6.802 \times 10^{-4}=13.604 \times 10^{-4}$

2. Stress range $=34 \mathrm{ksi} \quad$ Elastic strainrange $=\frac{34}{20.5 \times i \mathrm{C}^{3}}=1.659 \times 10^{-3}$

3. From elastic and plastic life relations (or cyclic stress stiain curve)

plastic strainrange for an ela: : strainrange of $1.659 \times 10^{-3}$ is $7.934 \times 10^{-5}$

4. $\Delta \varepsilon_{p p}=7.934 \times 10^{-5}, \Delta \varepsilon_{c c}=1.360 \times 10^{-3}, \Delta \varepsilon_{e}: 1.659 \times 10^{-3}$

5. $\Delta \varepsilon_{t}=\Delta \varepsilon_{p p}+\Delta \varepsilon_{c c}+\Delta \varepsilon_{e 1}=3.098 \times 10^{-3}$

E. $f_{p D}=\frac{? .934 \times 10^{-5}}{7.934 \times 10^{-5} \div 1.360 \times 10^{-3}}=.0551$

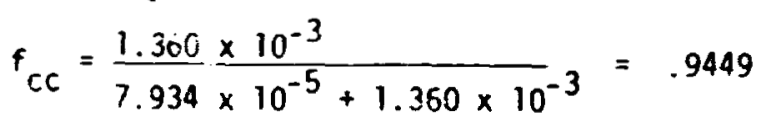

7. $\frac{1}{N_{f}}=\frac{f p p}{N_{p p}}=\frac{f c c}{N_{c r}}=\frac{.0551}{4.22 \times 10^{3}}+\frac{.3449}{1.60 \times 104}$

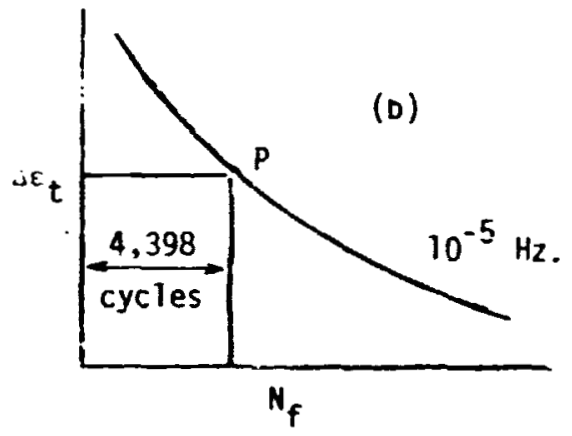

$$
\begin{aligned}
N_{f} & =4,3.98 \\
\Delta_{i} & =3.098 \times 10^{-3} \\
f & =10^{-5} \mathrm{~Hz}
\end{aligned}
$$

Fig. 15. illustrative computation for cortinuous stress ramping at iow frequency and strainrange 


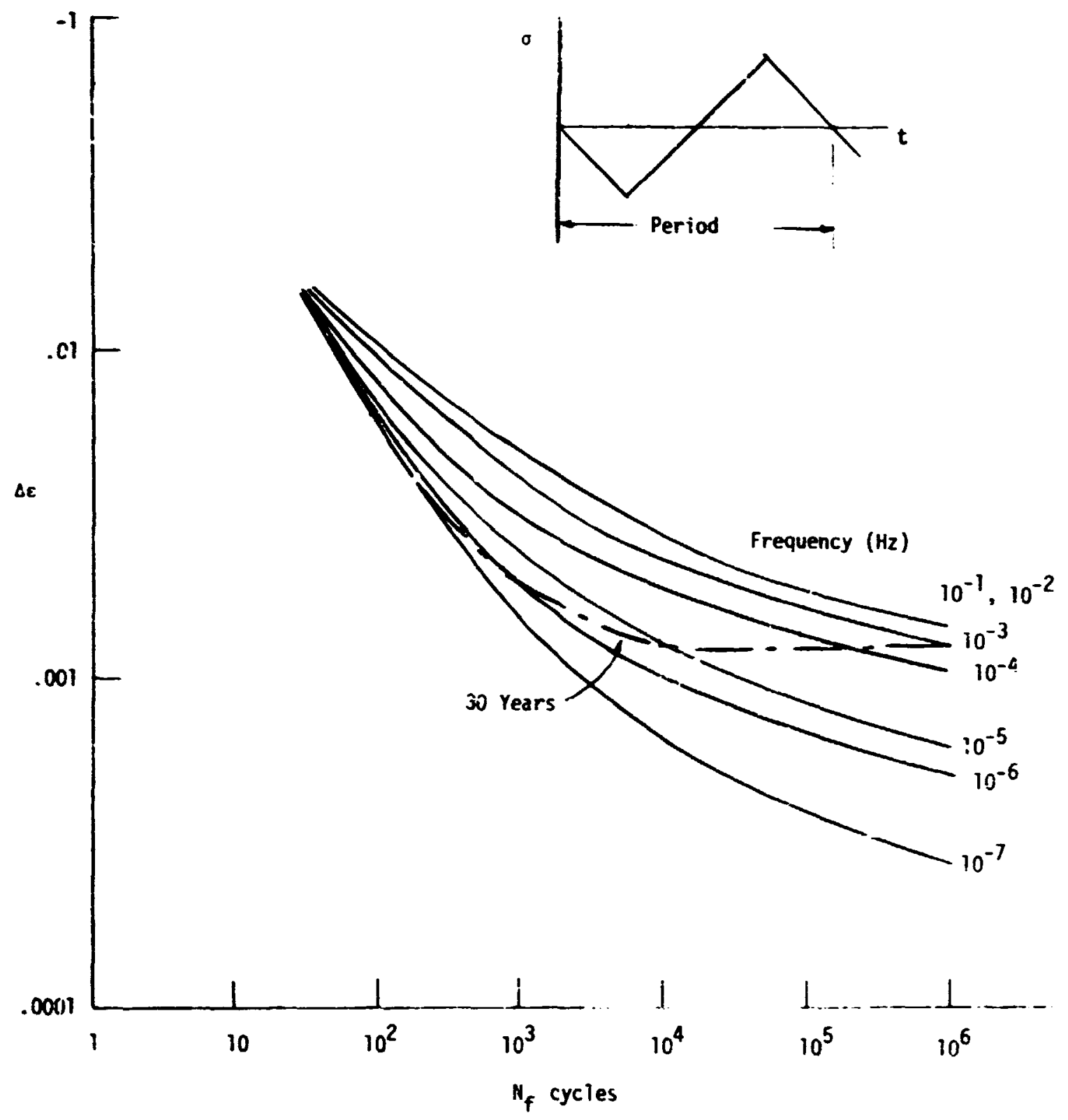

Fig. 16. Life relations in continuous stress raming, of $316 \mathrm{SS}$, at 1300F : with frequency as a parameter. 


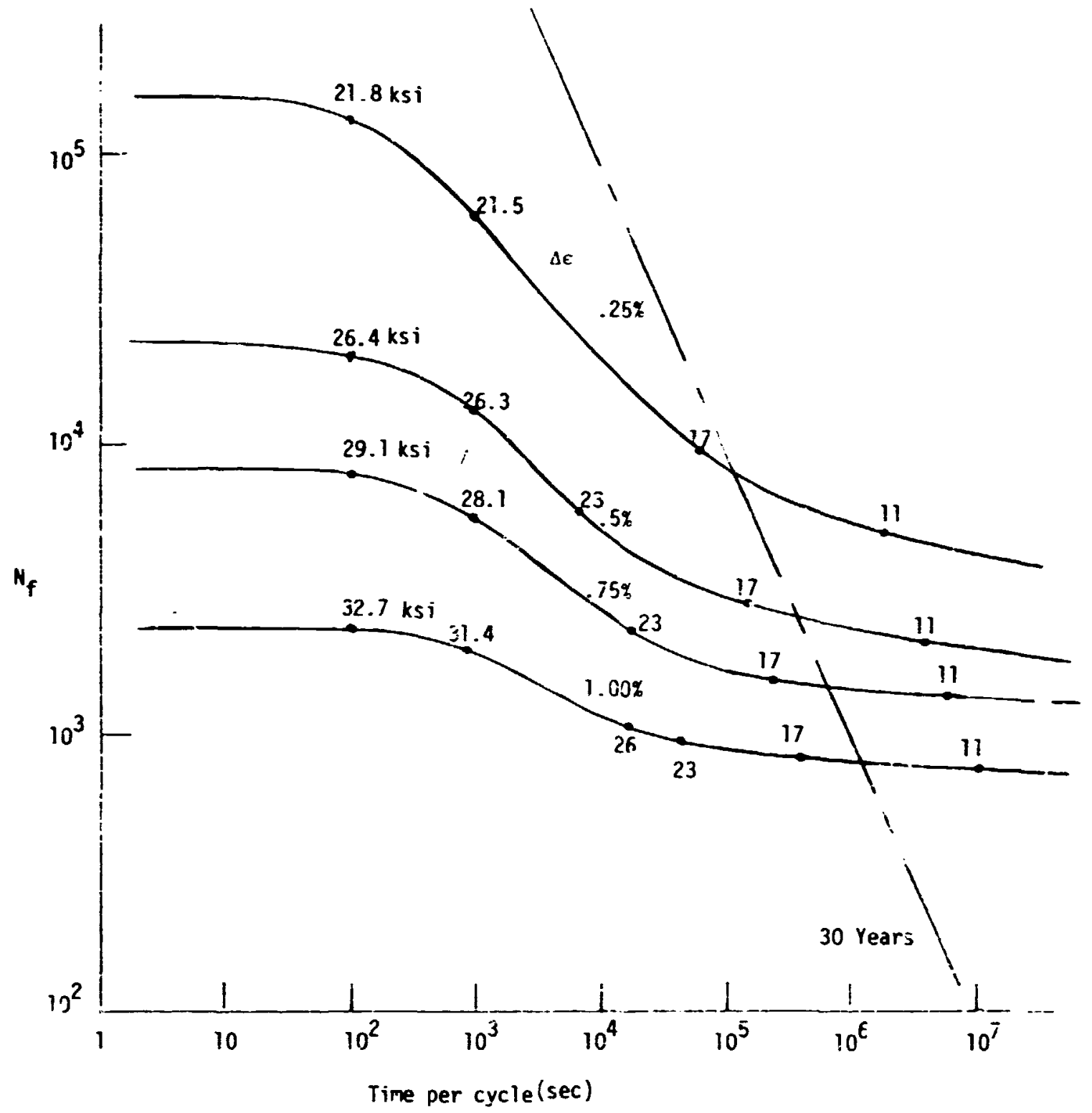

Fig. 17. Life Relations in continuous stress ramping, of $316 \mathrm{SS}$, at $1300 \mathrm{~F}$ : with strainrange as a parameter. 


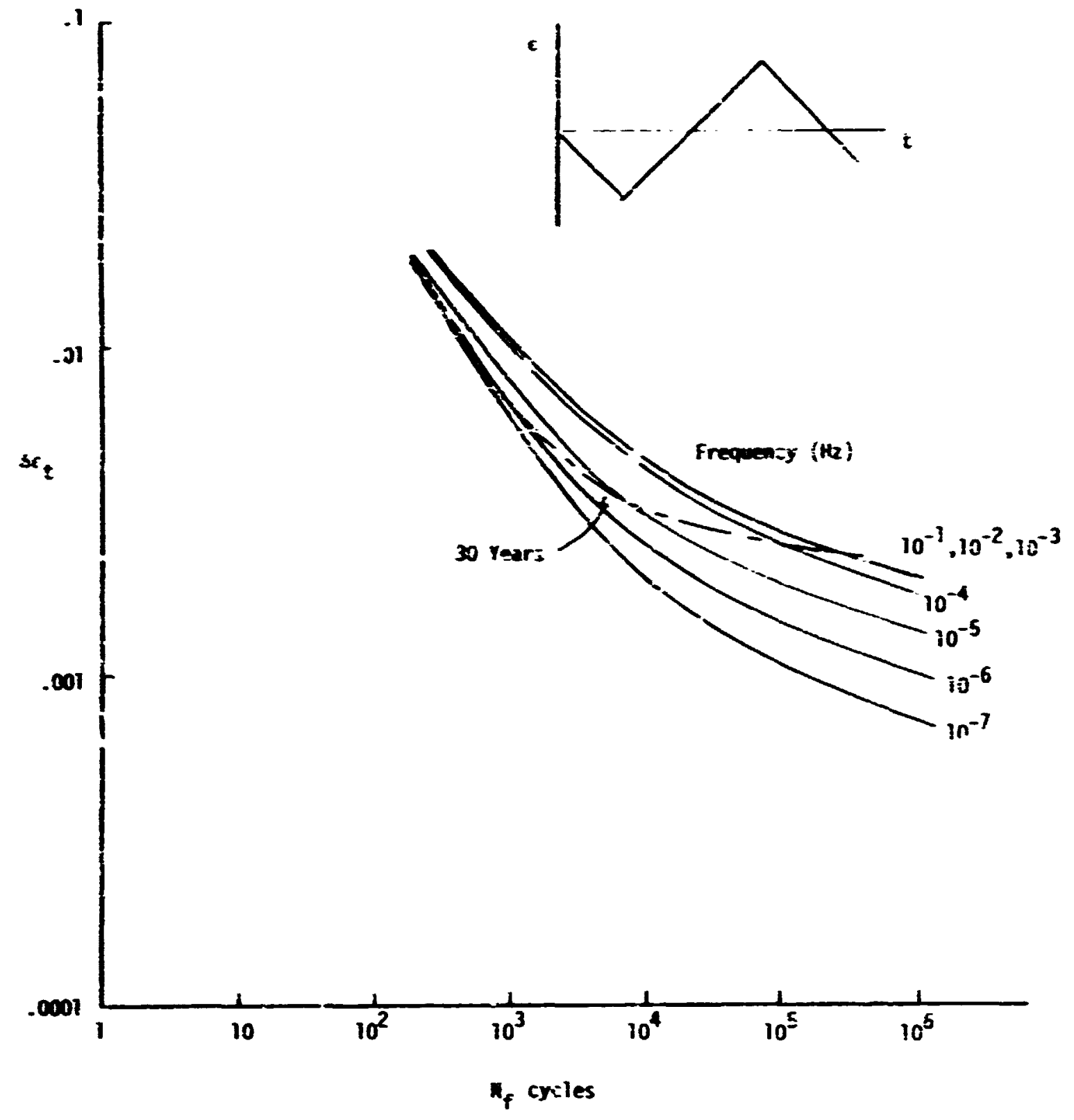

fig. 18. Stress rapiog, of $6 \mathrm{SS}$, at 1206F, witi frequency as a paraecter. 
53

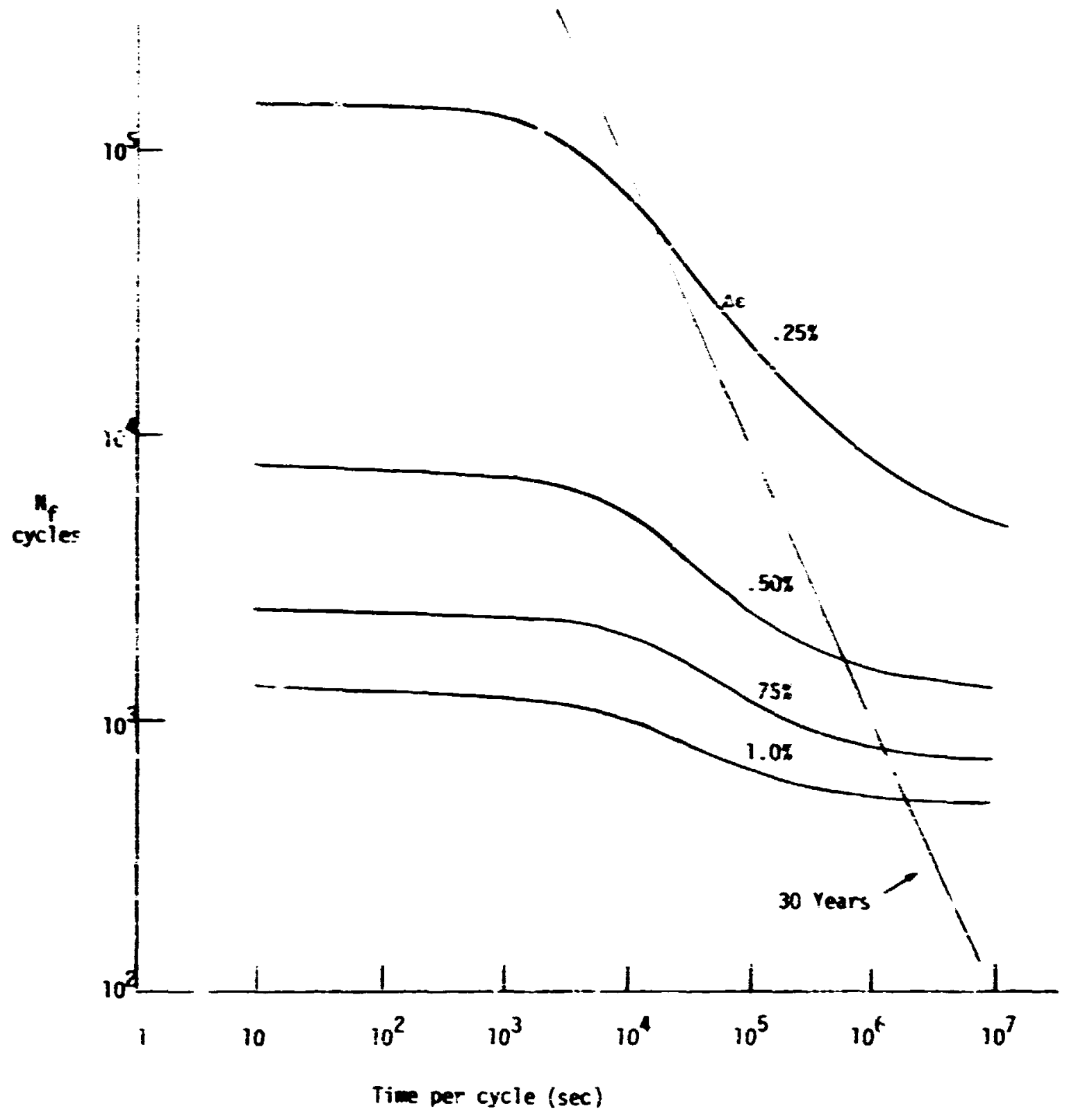

Fig. 19. Stress raping, of 316 SS, at 1200r, witn strainrange as a parameter. 


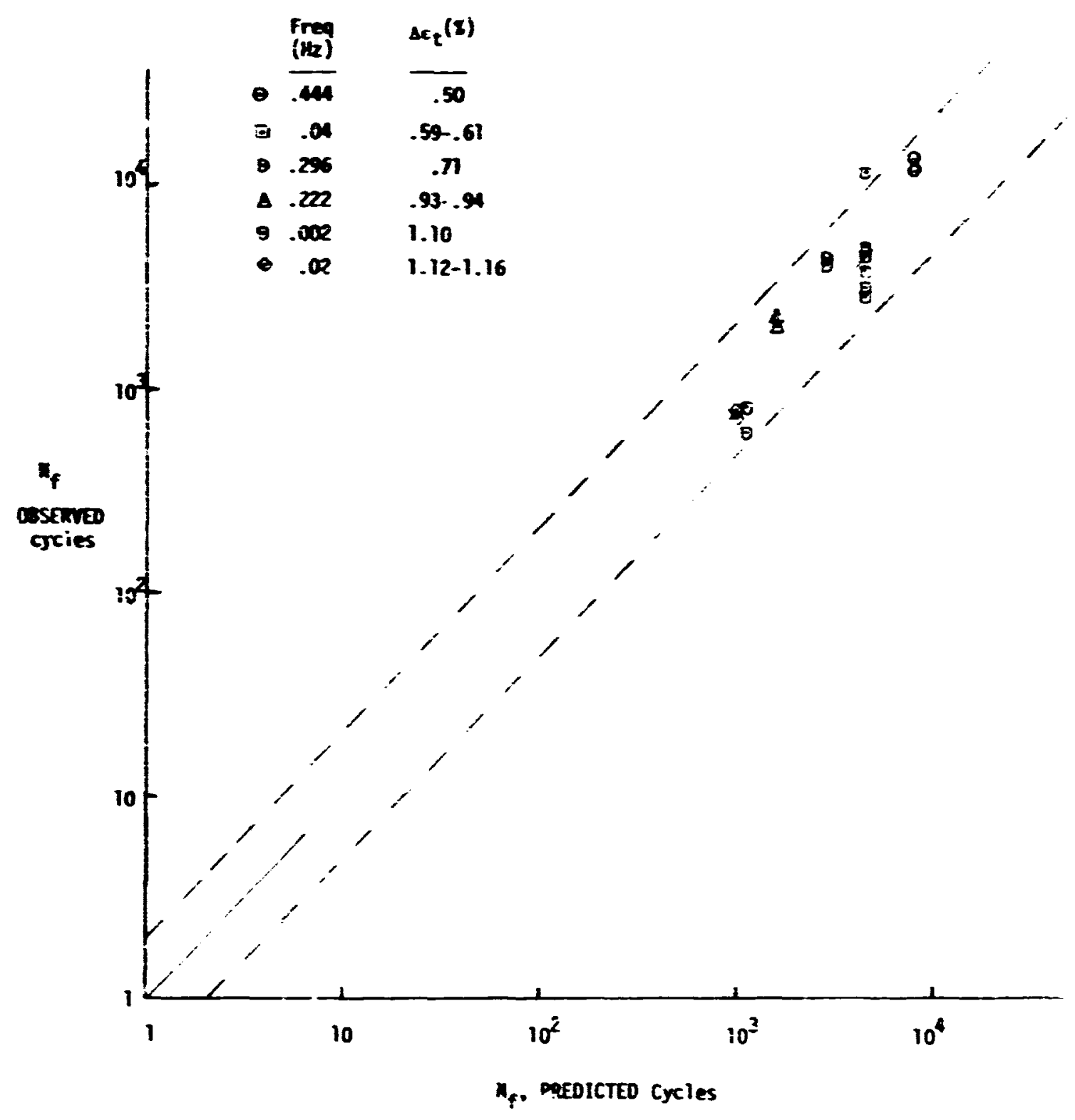

Fig. 20. Comarison of Predicted and Ixperimentzl life values for contimous strain cycling. Predictions ade from continuous stress raping calculations. Experiments deternined frow unifora strain remping, of 316 5S, at 12006 . 

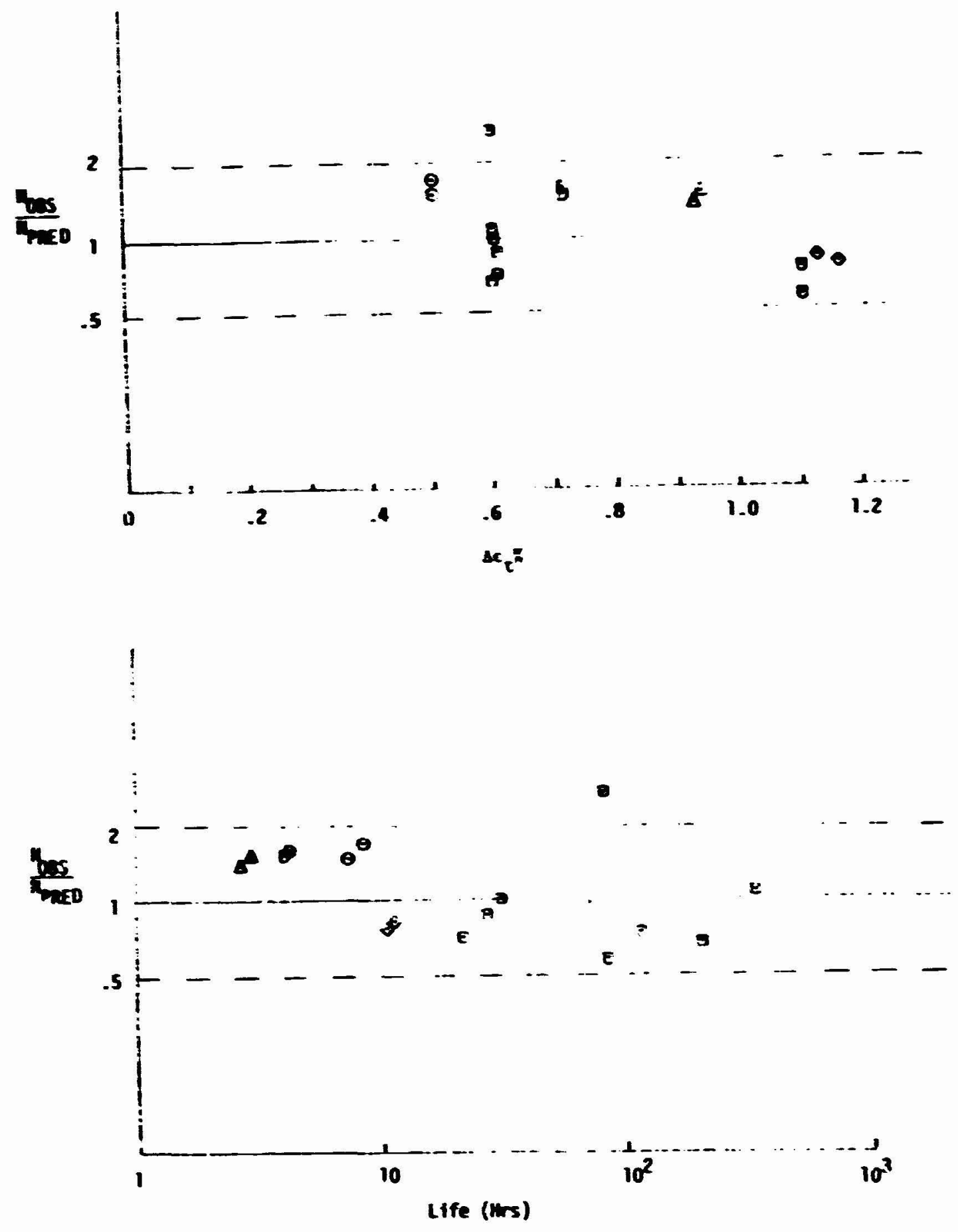

Fig. 20 (comt.) 


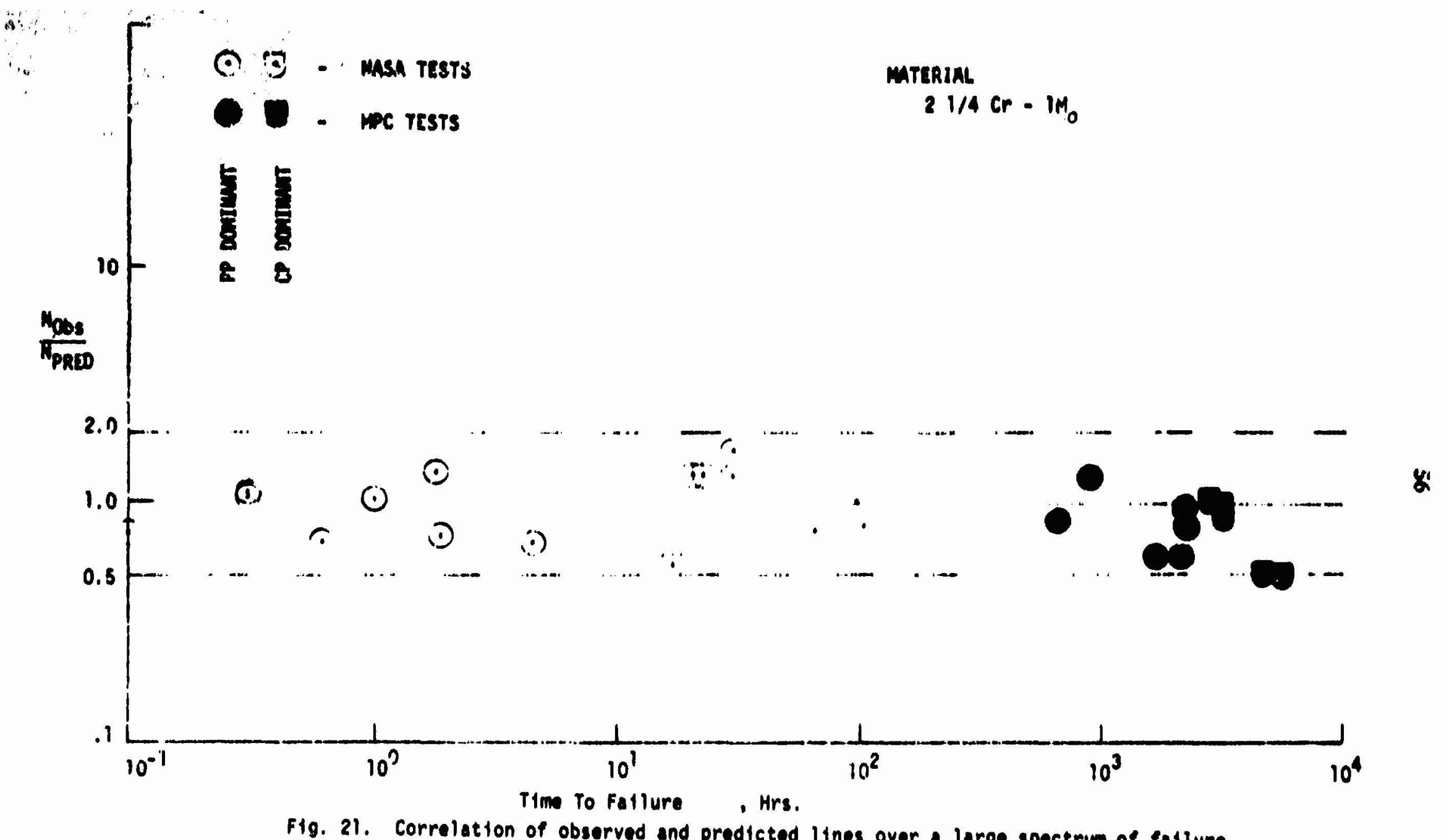

F19. 21. Correlation of observed and predicted lines over a large spectrum of fallure
times for $21 / 4 \mathrm{Cr}-1$ mo steel at $900-1100 \mathrm{~F}$. 


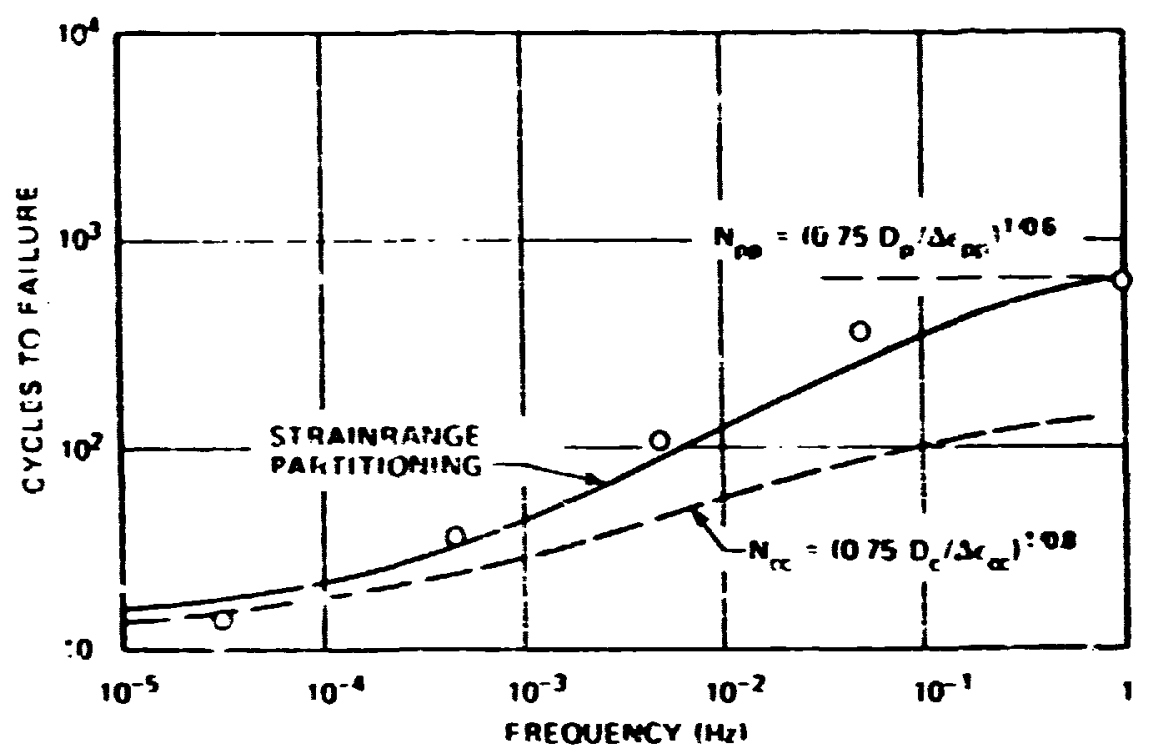

Fig. 22. Application of Strainrange Partitioning to study of frequency effect for a material with time-dependent creep ductility; A-286 tested at $1100^{\circ} \mathrm{F}\left(595^{\circ} \mathrm{C}\right), \Delta \varepsilon_{\text {in }}=0.009$. 

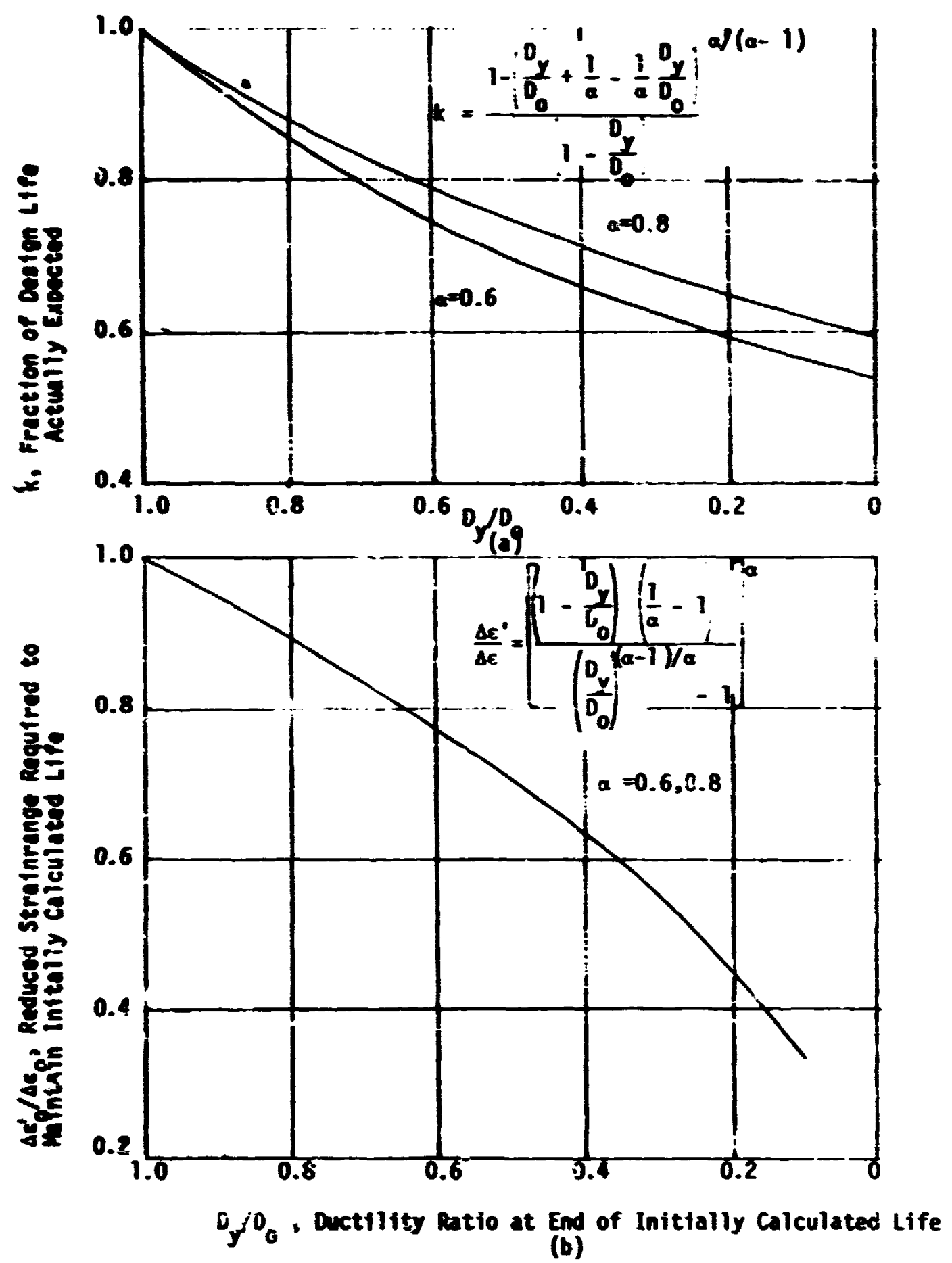

Fig. 23. Application of Stroinrange Partitioning to estimate Crittling effects. (a) Strainrange mintained constant, Iife reduced; (b) Strainrange reduced to restore life to faitfally calculated value. 


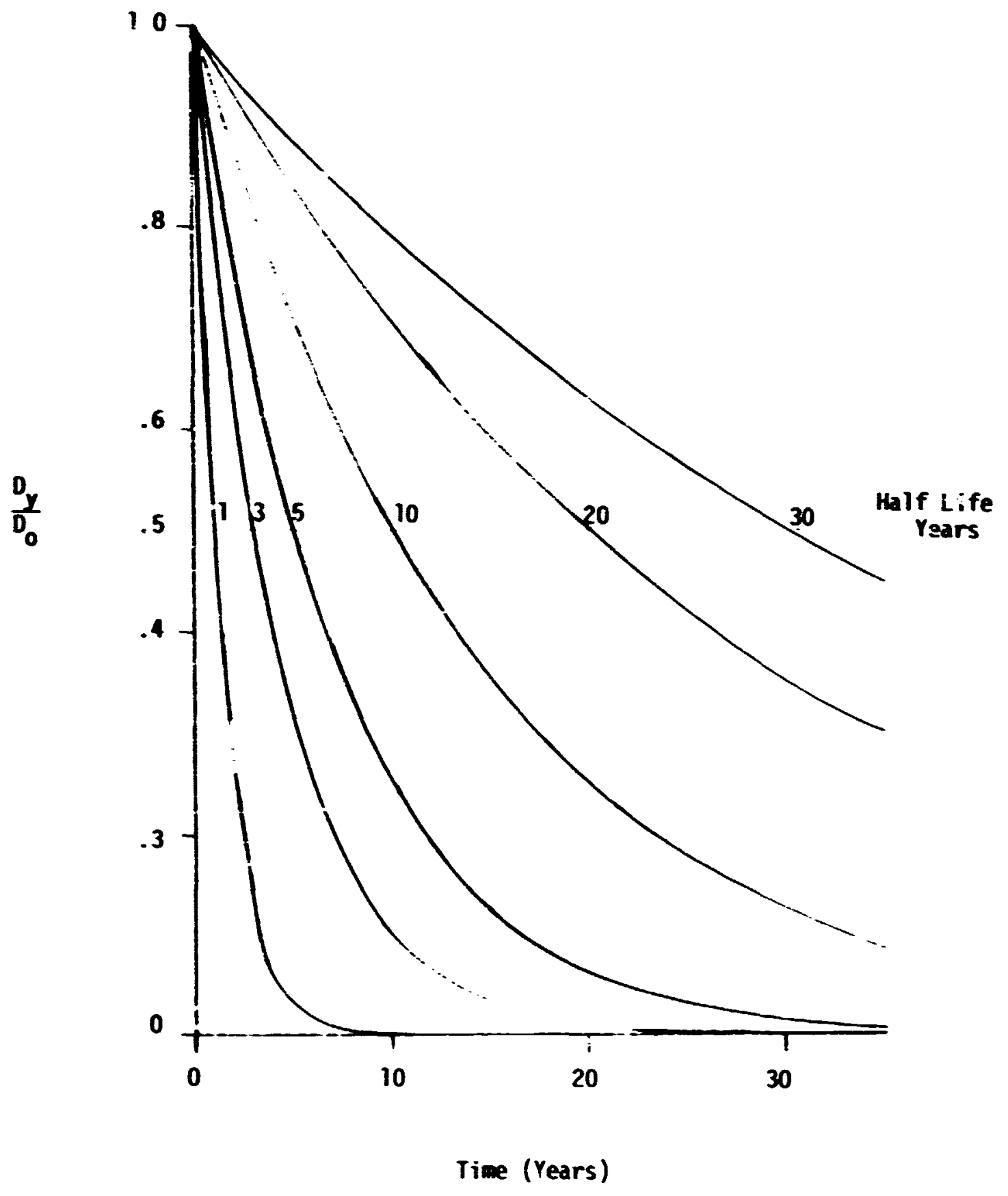

Fig. 24. Hypothesized inctility variations for use in life calculations 


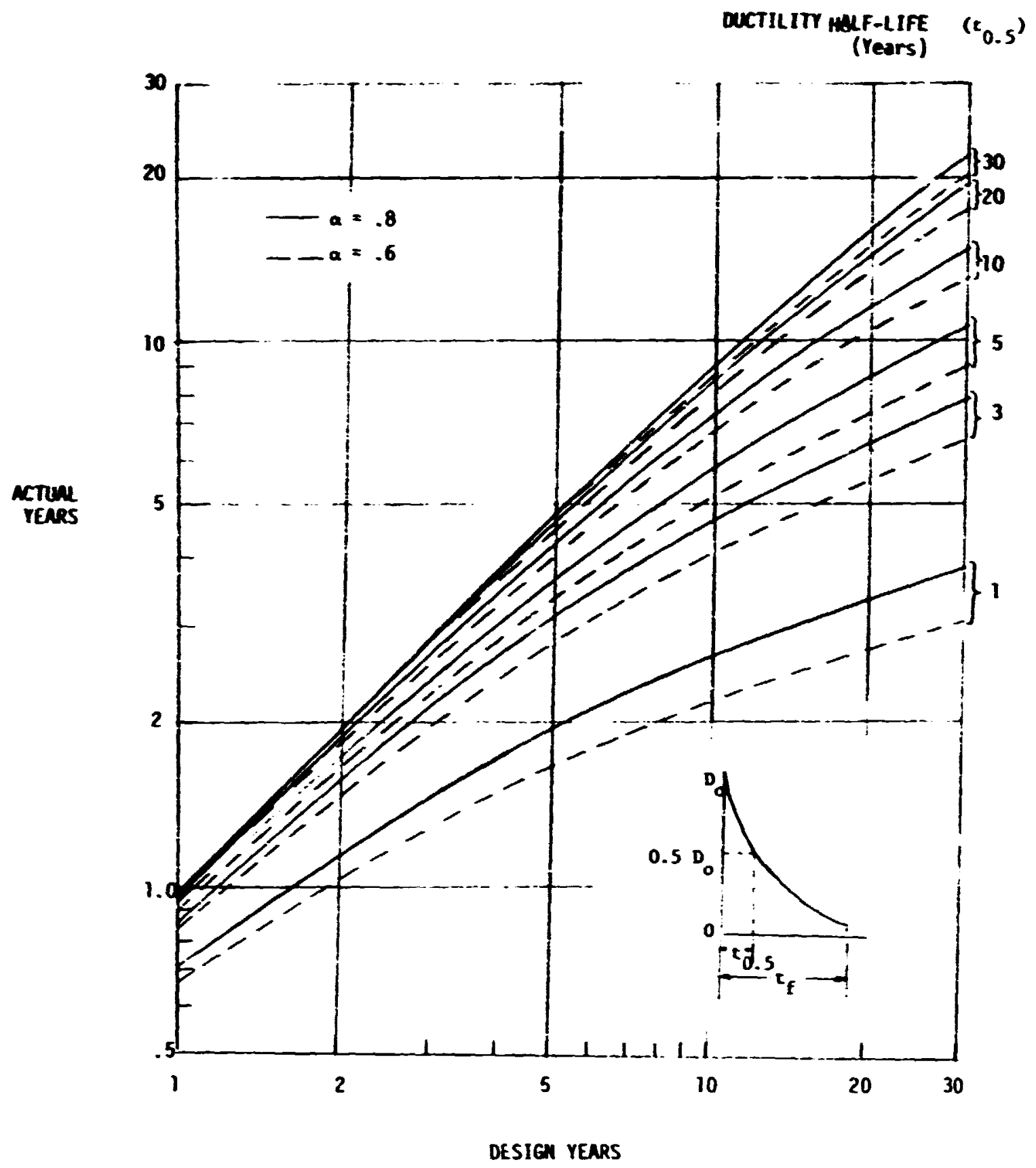

Fig. 25 Calculated fatigue life for exponential decay of ductility. 